\title{
Probing the carbon emissions in 30 regions of China based on symbolic regression and Tapio decoupling
}

\section{Haiying Liu}

India Ministry of Shipping Economics and Management,Dalian Maritime University zhiqun zhang ( $\nabla 15100272663 @ 163 . c o m)$

School of Shipping Economics and Management, Dalian Maritime University

\section{Research Article}

Keywords: Carbon emissions, GDP, regions, energy, Clustering, Tapio decoupling

Posted Date: April 1st, 2021

DOl: https://doi.org/10.21203/rs.3.rs-303069/v1

License: (c) (1) This work is licensed under a Creative Commons Attribution 4.0 International License.

Read Full License

Version of Record: A version of this preprint was published at Environmental Science and Pollution Research on August 10th, 2021. See the published version at https://doi.org/10.1007/s11356-021-15648$\mathrm{x}$. 


\section{Probing the carbon emissions in $\mathbf{3 0}$ regions of China based on}

\section{symbolic regression and Tapio decoupling}

Haiying Liu, Zhiqun Zhang

School of Maritime Economics and Management, Dalian Maritime University, Dalian, 116033, China

Corresponding Author:

Name: Zhiqun Zhang;

E-mail: 15100272663@163.com

Tel:+86-15100272663

\section{Abstract}

Against the background of energy shortages and severe air pollution, countries around the world are aware of the importance of energy conservation and emissions reduction; China is actively achieving emissions reduction targets. In this study, we use a symbolic regression to classify China's regions according to the degree of influencing factors, and calculate and analyze the inherent decoupling relationship between carbon emissions and economic growth in each region. Based on our results, we divided the 30 regions of the country into six categories according to the main influencing factors: GDP (13 regions), energy intensity (EI; 7 regions), industrial structure (IS; 3 regions), urbanization rate (UR; 3 regions), car ownership (CO; 2 regions), and household consumption level (HCL; 2 regions). Then, according to the order of the average carbon emissions in each region from high to low, these regions were further categorized as type-EI, type-UR, type-GDP, type-IS, type-CO, or type-HCL regions. The decoupling index of each region showed a downward trend; EI and GDP regions were the most notable contributors to emissions, based on which we provide policy recommendations.

Keywords: Carbon emissions; GDP; regions; energy; Clustering; Tapio decoupling

\section{Introduction}

Since the Industrial Revolution of the 19th century, the emissions of greenhouse gases, such as carbon dioxide, generated by human activities has increased sharply, exceeding the regulatory capacity of nature, which has led to an increase in global average temperatures and global warming (Shuai et al., 2018; Schandl et al., 2016). Carbon emissions are considered the main cause of global warming, such that reducing carbon emissions is a fundamental task for environmental protection and human survival and development (Shi et al., 2017). Various countries have actively been formulating schemes to control carbon dioxide emissions. Freitas and Kaneko (2011) utilized this method to study the occurrence of a decoupling between economic growth and energy-related $\mathrm{CO} 2$ emission from 2004 to 2009 in Brazil. Bellocchi al. (2018) evaluate the integration of electric vehicles in the Italian energy scenario and their synergy with electricity generation from renewable energy sources, identifying the impacts in terms of $\mathrm{CO} 2$ emissions, costs, and curtailments on a medium - long-term perspective.

Since the reform and opening up of China, the Chinese economy has maintained sustained high 
growth (Huang et al., 2019; Quan et al., 2020). Since the 1990s, China has accelerated the urbanization process, with remarkable results ( $\mathrm{Li}$ and Yao, 2009). The GDP rose from 6,133.9 billion yuan in 1995 to 74006.1 billion yuan in 2016, with an average annual increase of $12.59 \%$. The rapid development of the GDP has caused serious damage to the living environment, accompanied by substantial energy consumption and carbon dioxide emissions. At the same time, environmental security is threatening the normal life of human beings. Therefore, the problem of air pollution has recently garnered significant attention, expounding the urgency for a solution, which is a result of the rapid development of the economy, population growth, and the continuous increase in energy consumption. Countries must find solutions that allow economic development to be dependent on clean energy, thus reducing the use of fossil fuels.

To achieve emissions reduction targets, the Chinese government has formulated detailed policy plans. At the 2009 climate change conference in Copenhagen, the Chinese government promised to reduce its carbon intensity by $40-45 \%$ by 2020 as compared with 2005 . Later, in response to the Paris Agreement, which was enacted in 2015, China committed itself to reducing its carbon intensity by $60-65 \%$ by 2030 as compared with 2005 , where the total carbon emissions are expected to peak by 2030 (Wu et al., 2019). To accomplish these plans, the state distributes emissions reduction targets to provinces and cities to fundamentally achieve these emissions reduction plans (Shen et al., 2018). However, there are numerous differences among China's regions in terms of geographical conditions, resource endowments, and customs, and there is no unified emissions reduction plan. Therefore, the government should formulate a corresponding low-carbon economic strategy based on the details of each region (Yang et al., 2018). To reasonably achieve these goals, the relationship between carbon emissions and various influencing factors must be understood in different provinces to develop effective emissions reduction measures.

Although previous studies have analyzed the spatial clustering of carbon emissions in various provinces in China, the influencing factors involved were incomplete and did not fully reflect the actual situation in each region. The novelty of this study is based on the actual situation of 30 regions in China and the establishment of carbon emissions models based on symbol regression. We consider previously highlighted influencing factors on carbon emissions, including the GDP, energy intensity, urbanization rate, and industrial structure; introduce new factors, such as the household consumption level and car ownership; and use symbol regression to build a model to analyze the influence of these factors on carbon emissions. Based on the main influencing factors, we classify China' s 30 regions and analyze the internal impact between the economic scale and carbon emissions of each region to ultimately formulate corresponding policies that can be implemented at the national level.

The novelty of this study is three-fold. First, there is a lack of literature on the use of symbolic regression to analyze China's carbon emissions. We aim to address these deficiencies. Second, we use the advantages of symbolic regression to analyze the factors influencing China's carbon emissions. Based on previous studies, to more accurately analyze the detailed situation for China's carbon emissions, we introduce factors, such as the urbanization rate, household consumption level, and car ownership. Third, we combine symbolic regression and Tapio decoupling methods to analyze in detail the internal links between China's various regions and economic growth.

The remainder of this paper is organized as follows. Section 2 introduces the current research status on carbon emissions, symbol regression, and Tapio decoupling. Section 3 describes the methodological theory and data sources. In section 4 , we present the results of using the symbolic regression method to establish a carbon emissions model, classify the Chinese regions according to their main influencing 
factors, and then use the Tapio model for decoupling analysis. Section 5 presents the conclusions and policy recommendations.

\section{Literature Review}

Many experts pay close attention to economic growth and the relationship between energy consumption and environmental protection. From 1996 to 2013, China's carbon emissions increased by $227.43 \%$. The impact of economic growth mainly promoted an increase in carbon emissions, such that the key to reducing the energy intensity is to reduce carbon emissions. Changes in the energy structure also have a slight impact on the total emissions growth (Jiang et al., 2017). The development of urbanization has a positive effect on China's energy consumption and carbon dioxide emissions, which differ based on regional characteristics. Urbanization has a greater impact on $\mathrm{CO}_{2}$ emissions in central China than in eastern China (Liu et al., 2011; Zhang and Lin., 2012; Li and Zhou., 2019). Shahbaz et al. (2016) found that economic growth mainly affected the carbon dioxide emissions in Malaysia and that urbanization can reduce carbon emissions, whereas growth to a certain level promoted carbon dioxide emissions. For China, scholars have found that wealth and population effects are the first two factors in the growth of $\mathrm{CO}_{2}$ emissions in Xinjiang. The energy intensity effect has become the dominant factor in curbing carbon emissions (Wang et al., 2015). The population, urbanization level, per capita GDP, industrialization level, and service level were the main reasons for the growth of $\mathrm{CO}_{2}$ emissions in Guangdong Province (Wang et al., 2013). Other studies have found that technological change is the dominant factor in the decoupling of environmental pressures from economic growth in Chongqing from 1999-2000 while economic structural changes had a negative impact on carbon dioxide emissions (Yu et al., 2017).

Population growth and the regional per capita GDP contributed to $\mathrm{CO}_{2}$ emissions in the Beijing-Tianjin-Hebei region while effects on end-use structural changes remained unchanged for the $\mathrm{CO}_{2}$ emissions in Beijing and Hebei, but has a greater impact on Tianjin's carbon emissions (Fan et al., 2019). Pan et al. (2019) found that the GDP, industrialization, technological innovation, urbanization, population, and foreign direct investments were the most common factors for carbon intensity in 34 OECD countries based on the symbolic regression method. Wen et al. (2018) found that the existence of the M-curve model between the per capita $\mathrm{CO}_{2}$ emissions and per capita GDP, and total energy consumption, was consistent with the traditional model of the EKC curve; the L-curve model between energy intensity and per capita GDP performed well. Lin et al. (2019) conducted a quantile analysis of Shanghai's industrial carbon emissions, finding that urbanization had a significant impact on $\mathrm{CO}_{2}$ emissions, i.e., the leading factor for increasing carbon emissions, followed by the energy structure, industrial structure, economic growth, and energy efficiency. Enhancing the energy efficiency is an effective technique to reduce $\mathrm{CO}_{2}$ emissions and energy structures. The economic output, $\mathrm{R} \& \mathrm{D}$ intensity, investment intensity, and energy structure of the industrial sector in Henan Province were the driving factors for the increase in $\mathrm{CO}_{2}$ emissions from 2001 to 2015. In contrast, energy intensity, R\&D efficiency, and the internal industrial structure can reduce $\mathrm{CO}_{2}$ emissions (Liu et al., 2019). Production in the secondary industry has proven to be a major source of carbon emissions, with a relatively high emissions reduction potential (Zhang and Da, 2015). Kihoon and Wankeun (2006) explore the differences in $\mathrm{CO}_{2}$ emissions in APEC regions. Their main finding was that the per capita GDP and total population growth were the main factors contributing to the promotion of $\mathrm{CO}_{2}$ emissions. Moreover, the energy efficiency and fuel conversion have been considered the most promising areas by many experts (Kihoon and Wankeun, 2006). 
Symbolic regression is based on evolutionary computation, also known as function modeling (Dong and Hao, 2018). All variable values required for a particular objective function are transformed into a functional relationship using this method. Schmidt and Lipson (2009) found that symbolic regression can actively search for process data and find the Hamiltonian, Lagrangian, and other laws of geometric and momentum conservation. In contrast to other fitting methods, symbolic regression can find the relationships between invisible functions (Khu et al., 2010). Symbol regression sets parameters and symbols at the same time and can be considered a novel and efficient method. Wen et al. (2017) probed the major factors affecting carbon emissions via symbolic regression, indicating that Beijing and Tianjin had different carbon emission targets. Yang et al. (2015) used symbolic regression to probe the relationship between the GDP and carbon emissions using a straightforward regression function. On this basis, to more accurately fit the carbon emission formulas of various regions in China, they added more arithmetic symbols, such as sine, cosine, division, exponential, and power.

Decoupling distinguishes the relationship between economic gain and environmental stress, as defined by the OECD. Decoupling in a low-carbon economy refers to the following relationship: as the economy grows, carbon emissions begin to increase, but as the economy continues to grow, carbon emissions will decrease or even disappear. In fact, reducing energy consumption for economic growth is necessary. Therefore, the decoupling of carbon emissions refers to the economic growth elasticity of carbon emissions.

Luo et al. (2020) used the Tapio model to study the decoupling relationship between economic growth and resources in the Central Plains urban agglomeration, proposing relevant policies for a strong decoupling. Xie et al.(2020) used the Tapio decoupling model to analyze the decoupling index of $\mathrm{CO}_{2}$ emissions in the power industry, thereby realizing energy conservation and emissions reduction in this industry. Zhang et al. (2020) analyzed the decoupling relationship between economic output and carbon emissions in 11 provinces in the Yangtze River Basin (YREB), finding that the energy intensity (EI) effect was the main driving force for the decoupling of most provinces. Based on previous research, the Tapio decoupling method can analyze the elasticity state between economic growth and carbon emissions in detail.

\section{Materials and methods}

\subsection{Details of carbon emissions calculation}

The calculations were based on the carbon emission measurements presented by the IPCC Guidelines for National Greenhouse Gas Inventories (IPCC, 2006). Carbon emissions can be calculated as follows:

$$
C=\sum_{i} C_{i}=\sum_{i} E_{i} e_{i} f_{i}
$$

where $\mathrm{C}$ denotes the total carbon emissions, $C_{i}$ indicates the carbon emissions of the $i$ thergy type, $E_{i}$ is the consumption of the $i$ th energy type $\left(10^{4} \mathrm{t}, 108 \mathrm{~m}^{3}\right), e_{i}$ denotes the standard coal coefficient of the $i$ th energy type $\left(10^{4}\right.$ tce/t, 104 tce/108 $\left.\mathrm{m}^{3}\right)$, and $f_{i}$ is the carbon emissions coefficient of the $i$ th fuel type $\left(10^{4}\right.$ tcec/10 $10^{4}$ tce $)$. Table 1 lists the carbon emission coefficients of the fuels. 
Table 1. Carbon emissions coefficient of fuels.

\begin{tabular}{ccc}
\hline Energy type & Standard coal coefficient & Carbon emissions coefficient \\
\hline coal & 0.714 & 0.767 \\
coke & 0.971 & 0.856 \\
crude oil & 1.428 & 0.586 \\
gasoline & 1.471 & 0.554 \\
kerosene & 1.471 & 0.571 \\
diesel & 1.457 & 0.593 \\
fuel oil & 1.428 & 0.619 \\
natural gas & 1.330 & 0.448 \\
\hline
\end{tabular}

\subsection{Symbolic regression model}

Symbolic regression is a functional regression method that improves the genetic algorithm and can automatically search for the functional structure of a particular initial population (O'Reilly Una May, 2014; Bartosz and Jarosław, 2016). Compared with the general clustering method, symbol regression has the advantage of avoiding a decrease in the choice range using a pre-hypothesis model and decreases the probability of losing the potential model. Symbol regression can automatically establish relationships based on the internal properties of the data, similar to a robotic scientist. It finds the functional model with the highest fitness to show this relationship and determines the parameters and structure of each regression model (Vladislavleva et al., 2009; Khu et al., 2001). In addition, the eureqa software combines the advantages of symbol regression methods with simplicity and intelligence, such that many studies have used it in various application areas (Can and Heavey, 2011; Yang et al., 2016).

The core of symbolic regression is based on Darwin's theory of evolution, which selects important factors to gradually form a model and automatically separate non-existing factors from the model. This theory is based on the principle of genetic programming, the process of which is illustrated in Fig. 1. This approach helps researchers determine the contribution of each factor to a model. In other words, the presence of factors indicates existence while the frequency of occurrence indicates importance. 


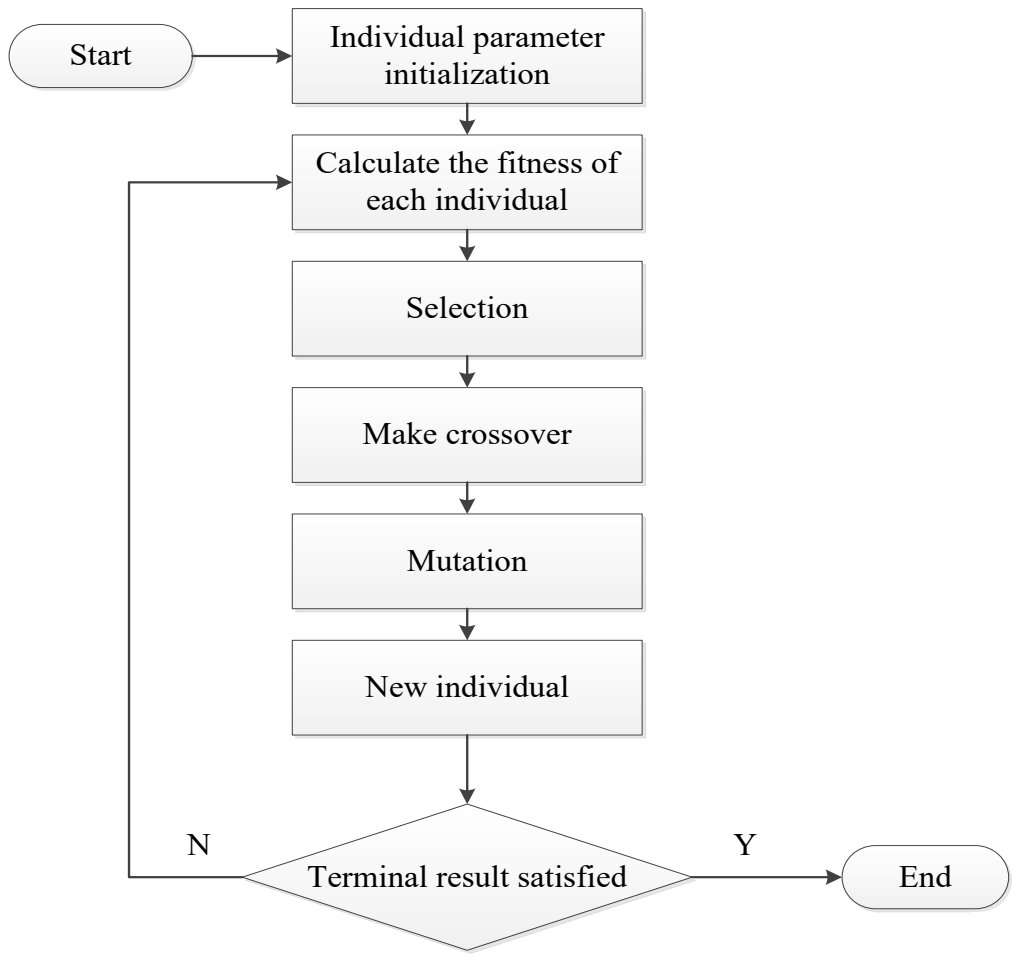

Fig. 1 Genetic planning of symbolic regression.

The Eureqa formula was used to solve the problem of modeling complex data using symbolic regression. Eureqa is a scientific data mining software package that solves most of the computationally heavy workload inherent in automated scientific processing. Symbolic regression has the advantage of rapidly and effectively finding models and parameters with high accuracy. In general, more complex candidate solutions may be more accurate, but the possibility of overfitting also increases. A simple and effective technique to control overfitting is to limit the complexity of the model. In this study, the complexity statistic (see below) was used to represent the complexity of the candidate solution. In the tree structure, each node expresses the complexity of the model by measuring the total number of nodes in the syntax tree, rendering the model more complex, as shown in Fig. 2.

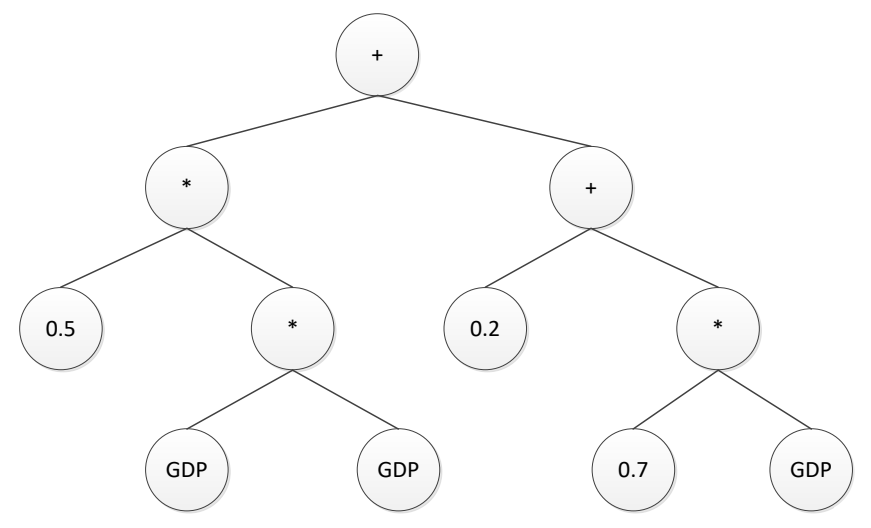

Fig. 2 Example of a tree structure in symbolic regression for the expression $0.5 * \mathrm{GDP}^{2}+0.7 * \mathrm{GDP}+0.2$.

Symbolic regression does not need to make assumptions in advance; rather, it can fit a series of candidate models and their parameters based on input and output. The complexity (C), R-squared $\left(\mathrm{R}^{2}\right)$, and fitness function (Fit) are often used to evaluate the advantages and disadvantages of the candidate models. Complexity (C) represents the complexity of the candidate model. In this study, the fitting 
accuracy was measured by the fitness measure, R-squared $\left(\mathrm{R}^{2}\right)$, calculated as in Eq. (2); the larger the $\mathrm{R}^{2}$ value, the higher the fitting accuracy of the equation:

$$
R^{2}=\frac{\sum_{i=1}^{n}\left(y_{i}-\bar{y}\right)^{2}-\sum_{i-1}^{n}\left(\mathrm{y}_{i}-\hat{y}\right)^{2}}{\sum_{i-1}^{n}\left(\mathrm{y}_{i}-\bar{y}\right)^{2}} .
$$

Fitness was used to evaluate personal strengths, retain high fitness individuals, and remove low-fitness individuals, calculated as in Eq. (3), where $\mathrm{Y}_{\mathrm{i}}$ is the actual value of the dependent variable, $\hat{y}$ indicates the predictive value, and $\bar{y}$ is the average value of the dependent variable:

$$
F \text { it }=\sum_{1}^{n}\left|y_{i}-\hat{y}_{i}\right| \text {. }
$$

\subsection{Tapio decoupling model}

This study adopts the Tapio decoupling model, which further divides the degree of decoupling on the basis of the OECD model, which is divided into eight categories. After a detailed division, the internal relationship between the environmental pressure and economic indicators can be evaluated in more detail.

Based on Tapio's decoupling methodology, this study built a decoupling framework between carbon emissions (C) and economic growth $(\mathrm{G})$, which seeks the relationship between the decoupling coefficient and decoupling model:

$$
D^{t}=\frac{\% C}{\% G}=\frac{\left(\mathrm{C}^{t}-C^{0}\right) / \mathrm{C}^{0}}{\left(G^{t}-G^{0}\right) / G^{0}},
$$

where $D^{t}$ is the decoupling exponent, $\% C$ is the percentage of carbon emissions, and $\% \mathrm{G}$ is the percentage of various influencing factors. Hence, on the basis of the definition in Tapio (2005), eight decoupling states are expressed in Table 2.

Table 2. Distribution of the decoupling states in the energy industrial sector.

\begin{tabular}{cccc}
\hline$D^{t}$ & $\% C$ & $\% \mathrm{G}$ & Decoupling state \\
\hline$(-\infty, 0]$ & $<0$ & $>0$ & Strong decoupling \\
$(0,0.8]$ & $>0$ & $>0$ & Weak decoupling \\
$(1.2,+\infty]$ & $<0$ & $<0$ & Recessive decoupling \\
$(\infty, 0]$ & $>0$ & $<0$ & Strong negative decoupling
\end{tabular}




$\begin{array}{llcc}(0,0.8] & <0 & <0 & \text { Weak negative decoupling } \\ (1.2+\infty] & >0 & >0 & \text { Expansive negative decoupling } \\ (0.8,1.2] & <0 & >0 & \text { Recessive coupling } \\ (0.8,1.2] & >0 & \text { Expansive coupling }\end{array}$

\subsection{Data description}

We selected a variety of variables as indicators that affect environmental pollution and screened the main factors according to the actual situation in each province. The data resources covered in this studies derive from the China Statistical Yearbook (CSY) and the statistical yearbooks of the 30 investigated regions from 1995-2016. The energy unit was the standard coal consumption in $10^{4}$ tce. Nine types of energies were employed in this study, including coal, coke, crude oil, gasoline, kerosene, diesel, fuel oil, and natural gas. In addition to the Tibet Autonomous Region, Hong Kong, Macao, and Taiwan were also included.

Table 3. Variables and units.

\begin{tabular}{lcc}
\hline Variable nature & Variable description & Unit \\
\hline $\begin{array}{c}\text { Dependent variable } \\
\text { Independent } \\
\text { variables }\end{array}$ & Carbon Emissions (C) & $10^{4}$ tce \\
& Gross Domestic Product (GDP) & $10^{8}$ yuan \\
& Urbanization rate (UR) & percent \\
Household consumption level (HCL) & percent \\
Industrial structure (IS) & yuan \\
Car ownership (CO) & percent
\end{tabular}

For the sake of completeness with respect to the influencing factors on carbon emissions in the country and provinces, we considered six independent variables, i.e., the GDP, EI, UR, HCL, IS, and $\mathrm{CO}$. $\mathrm{CO}$ includes the number of civilian passenger cars, the number of civilian trucks and private passenger cars, and the number of private trucks. A detailed description of each variable is provided in Table 3. As China implements the family planning policy, the population factor changes little, and the total population and urbanization have a collinear relationship. Therefore, we did not use population factors.

\section{Results and discussion}

\subsection{Symbolic regression}

We used symbolic regression to cluster 30 provinces, cities, and regions in China based on the influencing factors. We calculated the carbon emissions in these 30 regions from 1995 to 2016 using the carbon emissions calculation formula presented above. The research data in Fig. 3 indicate that 
China's carbon emissions showed an increasing trend, starting with an average annual growth rate of $5.63 \%$. Since 2014, under the influence of the national energy conservation and emissions reduction policy, the nation's carbon emissions have shown an increasing trend, with an average annual reduction rate of $1.28 \%$. Overall, the trend in China's carbon emissions from 1995 to 2016 was variable. The direct reason for this is the effect of the carbon emissions of various regions. The relationship between the carbon emissions in each region is analyzed below in detail.

We used the Eureqa software to fit a complex formula for carbon emissions in each province. When using the symbol regression method, common operators were selected in the model: constants, input variables, + (addition), - (subtraction), * (multiplication), / (division), sin ( $\sin ), \cos$ (cosine), division, exp (exponential), and power. We further explored the factors that appeared in the best models. We used Chongqing as an example to demonstrate our symbolic regression approach. The search process for factors in the other 30 regions was consistent with that in Chongqing.

Based on a large number of alternative models, we established a Pareto front. The most suitable model is generally assumed to be located at the front of the Pareto, which is suitable for simultaneously balancing the fitting accuracy and model complexity (Jin and Bernhard, 2008). After the Pareto front had been accomplished, we focused on the Pareto front model. For researching pivotal factors and models, symbol regression was repeated. The Pareto front for Chongqing is shown in Fig. 4, and the model that suited the results best was chosen. Moreover, the best model that often appears at the Pareto front may be considered more likely to be associated with real relationships.

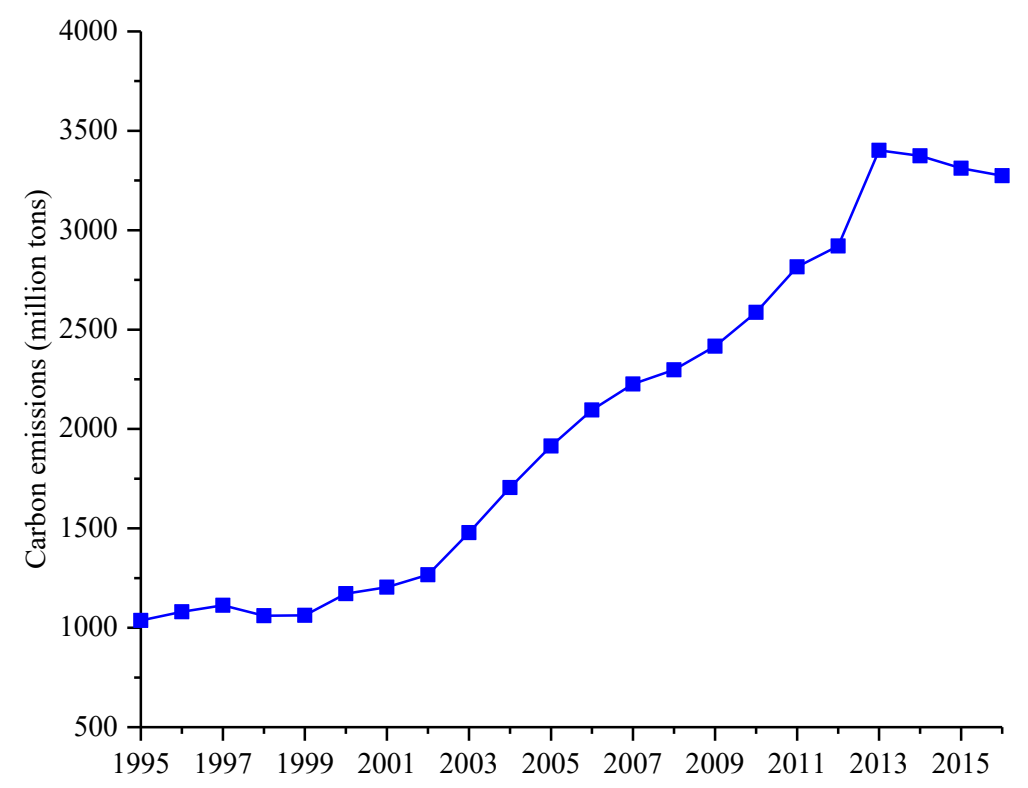

Fig. 3 Changes in the carbon emissions in the 30 regions of China. 


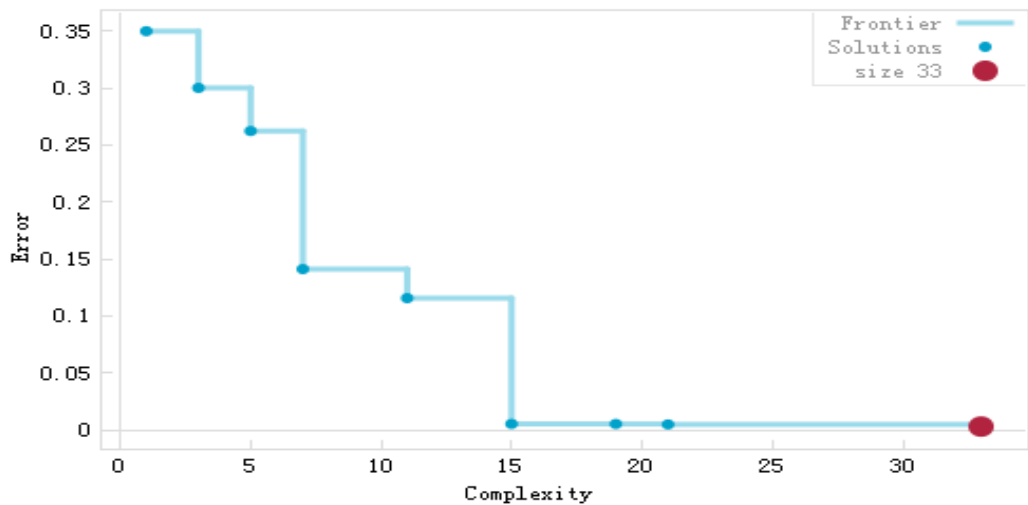

Fig. 4 Pareto front in Chongqing.

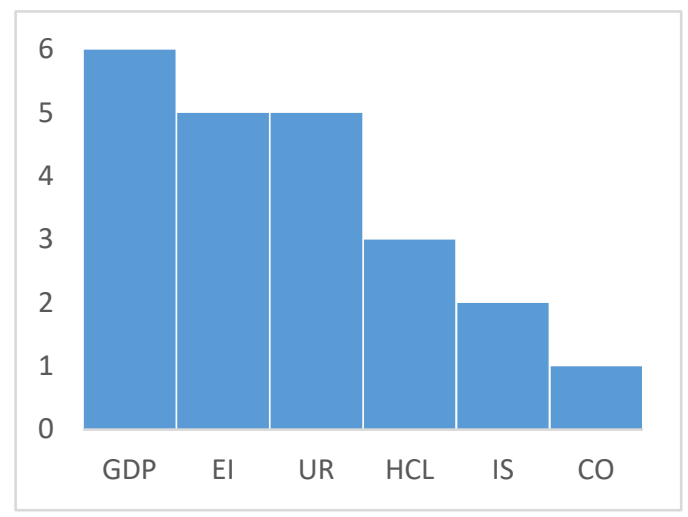

Fig. 5 Number of models each variable appears in for Chongqing.

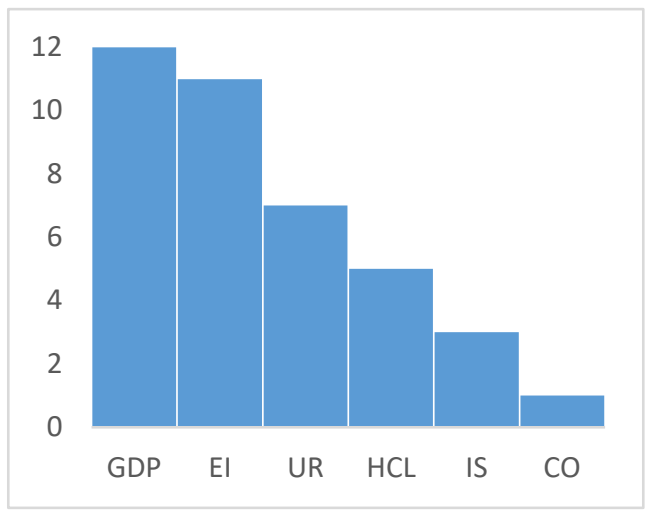

264 Fig. 6 Number of occurrences of each variable in Chongqing (across all models).

265 Table 4 Model collection in Chongqing's symbolic regression.

\begin{tabular}{llll}
\hline $\mathrm{R}^{2}$ & Size & Fit & Solution \\
\hline 0.99998 & 33 & 0.0083 & $\mathrm{C}=500.0402+0.7961 * \mathrm{GDP} * \mathrm{EI}+0.3017 * \mathrm{UR} * \mathrm{HCL}+1.5059 \mathrm{e}-6 * \mathrm{EI} *$ \\
& & & $\mathrm{GDP}^{2}-0.0685^{*} \mathrm{GDP}-0.1376 * \mathrm{HCL}-117.6373 * \mathrm{EI}-676.2056 * \mathrm{UR}-$ \\
& & & $1.4526 \mathrm{e}-6 * \mathrm{GDP}^{2}$
\end{tabular}




\begin{tabular}{|c|c|c|c|}
\hline 0.99996 & 21 & 0.0136 & $\begin{array}{l}\mathrm{C}=204.3704+0.7773 * \mathrm{GDP} * \mathrm{EI}+0.0479 * \mathrm{UR} * \mathrm{HCL}-0.0218 * \mathrm{HCL}- \\
0.0238^{*} \mathrm{GDP}-56.3436 * \mathrm{EI}-365.7719 * \mathrm{UR}\end{array}$ \\
\hline 0.99995 & 19 & 0.0148 & $\begin{array}{l}\mathrm{C}=19.0089 * \mathrm{EI}+0.0032 * \mathrm{HCL}+0.7595 * \mathrm{GDP} * \mathrm{EI}-24.1665-0.0134 * \\
\mathrm{GDP}\end{array}$ \\
\hline 0.99994 & 15 & 0.0149 & $\mathrm{C}=19.0089 * \mathrm{EI}+0.7595^{*} \mathrm{GDP} * \mathrm{EI}-21.6080-0.0097 * \mathrm{GDP}$ \\
\hline 0.97631 & 11 & 0.3305 & $\begin{array}{l}\mathrm{C}=37664.5696 * \mathrm{IS}+18190.4304 * \mathrm{EI}+13051.5396 * \mathrm{UR}-21011.4968- \\
39049.1808 * \mathrm{EI} * \mathrm{IS}\end{array}$ \\
\hline 0.96836 & 7 & 0.4033 & $\mathrm{C}=11722.7606 * \mathrm{IS}+0.1752 * \mathrm{GDP}-3631.6451$ \\
\hline 0.88816 & 5 & 0.7496 & $\mathrm{C}=1303.2643+0.4328 * \mathrm{GDP}-6.7332 * \mathrm{CO}$ \\
\hline 0.83874 & 3 & 0.8577 & $\mathrm{C}=8605.6128 * \mathrm{UR}-1035.2152$ \\
\hline 0.84929 & 1 & 1 & $C=10794.3886 * U R-2033.2884$ \\
\hline
\end{tabular}

Table 4 lists the results of the symbol regression. We listed the $\mathrm{R}^{2}$, complexity, and fit values, where lower complexity models typically do not perform well. However, models with higher complexity have the highest $\mathrm{R}^{2}$ and lowest fit value. Therefore, the best model for considering all indicators was as follows:

$$
\begin{aligned}
& C=500.0402+0.7961 * G D P * E I+0.3017 * U R^{*} H C L+1.5059 e^{-6} * E I * G D P^{2} \\
& -0.0685 * G D P-0.1376 * H C L-117.6373 * E I-676.2056 * U R-1.4526 e^{-6} * G D P^{2}
\end{aligned} .
$$

Figure 5 shows the relative importance of the various influencing factors derived from the symbol regression. Figure 6 shows the number of models that appear for each variable. For example, the GDP appeared in six models while CO only appeared in one model on the Pareto border in Chongqing. The most common variable was the GDP while CO was the least common variable. The GDP appeared 12 times in all models while CO only appeared once in Chongqing. Therefore, the GDP was the most influential factor for Chongqing's carbon emissions.

Table 5 Regional categories based on factors affecting the carbon emissions and corresponding $\mathrm{R}^{2}$.

\begin{tabular}{cccccccccc}
\hline R ${ }^{2}$ & Fit & Region & A & B & C & D & E & F & 0 \\
\hline Type-GDP & & & & & & & & & \\
0.999293 & 0.021 & Beijing & GDP & EI & CO & IS & UR & HCL & - \\
0.999999 & 0.004 & Inner Mongolia & GDP & EI & IS & CO & UR & - & HCL \\
0.999908 & 0.029 & Heilongjiang & GDP & EI & UR & IS & CO & HCL & - \\
0.999993 & 0.008 & Jiangsu & GDP & EI & IS & HCL & CO & UR & - \\
0.999984 & 0.009 & Henan & GDP & EI & UR & CO & IS & HCL & - \\
\hline
\end{tabular}




\begin{tabular}{cccccccccccc}
\hline 0.999997 & 0.009 & Shanxi & GDP & EI & IS & HCL & CO & - & UR \\
0.999982 & 0.003 & Qinghai & GDP & EI & IS & CO & HCL & UR & - \\
0.999965 & 0.016 & Ningxia & GDP & EI & UR & CO & HCL & - & IS \\
0.999981 & 0.008 & Chongqing & GDP & EI & UR & HCL & IS & CO & - \\
0.999944 & 0.007 & Shanghai & GDP & EI & CO & HCL & UR & IS & - \\
0.999943 & 0.007 & Guangxi & GDP & EI & CO & IS & HCL & - & UR \\
0.999959 & 0.007 & Yunnan & GDP & EI & CO & IS & HCL & - & UR \\
0.999984 & 0.037 & Xinjiang & GDP & EI & CO & IS & UR & HCL & -
\end{tabular}

Type-EI

$\begin{array}{lllllllllll}0.999931 & 0.019 & \text { Liaoning } & \text { EI } & \text { UR } & \text { GDP } & \text { IS } & \text { HCL } & \text { CO } & - \\ 0.999992 & 0.01 & \text { Shandong } & \text { EI } & \text { GDP } & \text { HCL } & \text { CO } & \text { IS } & \text { UR } & \text { - } \\ 0.999957 & 0.017 & \text { Hainan } & \text { EI } & \text { GDP } & \text { CO } & \text { UR } & \text { IS } & - & \text { HCL } \\ 0.999994 & 0.007 & \text { Hebei } & \text { EI } & \text { GDP } & \text { CO } & \text { UR } & \text { IS } & \text { HCL } & - \\ 0.999979 & 0.011 & \text { Hubei } & \text { EI } & \text { IS } & \text { GDP } & \text { CO } & \text { HCL } & - & \text { UR } \\ 0.999945 & 0.016 & \text { Sichuan } & \text { EI } & \text { GDP } & \text { CO } & \text { UR } & \text { IS } & - & \text { HCL } \\ 0.999986 & 0.008 & \text { Shanxi } & \text { EI } & \text { GDP } & \text { UR } & \text { CO } & \text { IS } & \text { HCL } & -\end{array}$

\section{Type-CO}

$\begin{array}{llllllllllll}0.999907 & 0.03 & \text { Tianjin } & \text { CO } & \text { EI } & \text { GDP } & \text { UR } & \text { IS } & \text { HCL } \\ 0.999962 & 0.007 & \text { Anhui } & \text { CO } & \text { UR } & \text { EI } & \text { HCL } & \text { GDP } & \text { IS } & - \\ 0.999971 & 0.008 & \text { Hunan } & \text { CO } & \text { GDP } & \text { IS } & \text { UR } & \text { EI } & \text { HCL } & -\end{array}$

\section{Type-IS}

$\begin{array}{cccccccccc}0.999195 & 0.056 & \text { Jiangxi } & \text { IS } & \text { EI } & \text { GDP } & \text { UR } & \text { HCL } & \text { CO } & - \\ 0.999974 & 0.019 & \text { Zhejiang } & \text { IS } & \text { GDP } & \text { UR } & \text { EI } & \text { HCL } & \text { CO } & \text { - } \\ 0.999953 & 0.019 & \text { Jilin } & \text { IS } & \text { EI } & \text { GDP } & \text { UR } & \text { CO } & - & \text { HCL }\end{array}$

\section{Type-HCL}

$\begin{array}{llllllllll}0.999839 & 0.027 & \text { Fujian } & \text { HCL } & \text { CO } & \text { EI } & \text { GDP } & \text { UR } & \text { IS } & - \\ 0.994867 & 0.112 & \text { Guizhou } & \text { HCL } & \text { GDP } & \text { EI } & \text { CO } & \text { IS } & \text { UR } & -\end{array}$




\section{Type-UR}

$\begin{array}{cccccccccc}0.999960 & 0.024 & \text { Guangdong } & \text { UR } & \text { HCL } & \text { CO } & \text { GDP } & \text { EI } & \text { IS } & - \\ 0.999949 & 0.009 & \text { Gansu } & \text { UR } & \text { GDP } & \text { EI } & \text { CO } & \text { IS } & - & \text { HCL }\end{array}$

Pareto fronts were obtained for every province, and the influential factors on carbon emissions were probed in each of these provinces. We analyzed the occurrence of each influencing factor in the Pareto optimal models and classified the influencing factors. The classifications were A, B, C, D, E, F, and 0 . A to $\mathrm{F}$ represent the number of occurrences from higher to lower, and 0 is an unrelated factor. "-." indicates that no influencing factors appear in the respective classification.

Table 5 describes the classification of each region according to the number of occurrences of influencing factors and the $\mathrm{R}^{2}$ values correspond to the optimal model. To classify the performance of each influencing factor in classification $\mathrm{A}$, we divided the 30 regions into six categories, classified by the importance of each influencing factor: Type-GDP, Type-EI, Type-CO, Type-IS, Type-HCL, and Type-UR. Type-GDP included Beijing, Inner Mongolia, Heilongjiang, Jiangsu, Henan, Shaanxi, Qinghai, Ningxia, Chongqing, Shanghai, Guangxi, Yunnan, and Xinjiang. Type-EI included Liaoning, Shandong, Hainan, Hebei, Hubei, Sichuan, and Shanxi. This is consistent with the conclusions of Song et al. (2020) who stated that in cities in the Bohai Rim Economic Circle, the energy intensity effect had the greatest impact on the carbon emissions intensity. Type-CO included Tianjin, Anhui, and Hunan. Type-IS included Jiangxi, Zhejiang, and Jilin. Type-HCL included Fujian and Guizhou, and Type-UR included Guangdong and Gansu.

This classification is illustrated in Fig. 7, where 0 represents the regions not considered (Tibet Autonomous Region, Hong Kong, Macao and Taiwan), “1” represents Type-GDP regions, “2” represents Type-EI regions, "3" represents Type-CO regions, "4" represents Type-IS regions, "5" represents Type-HCL regions, and "6" represents Type-UR regions.

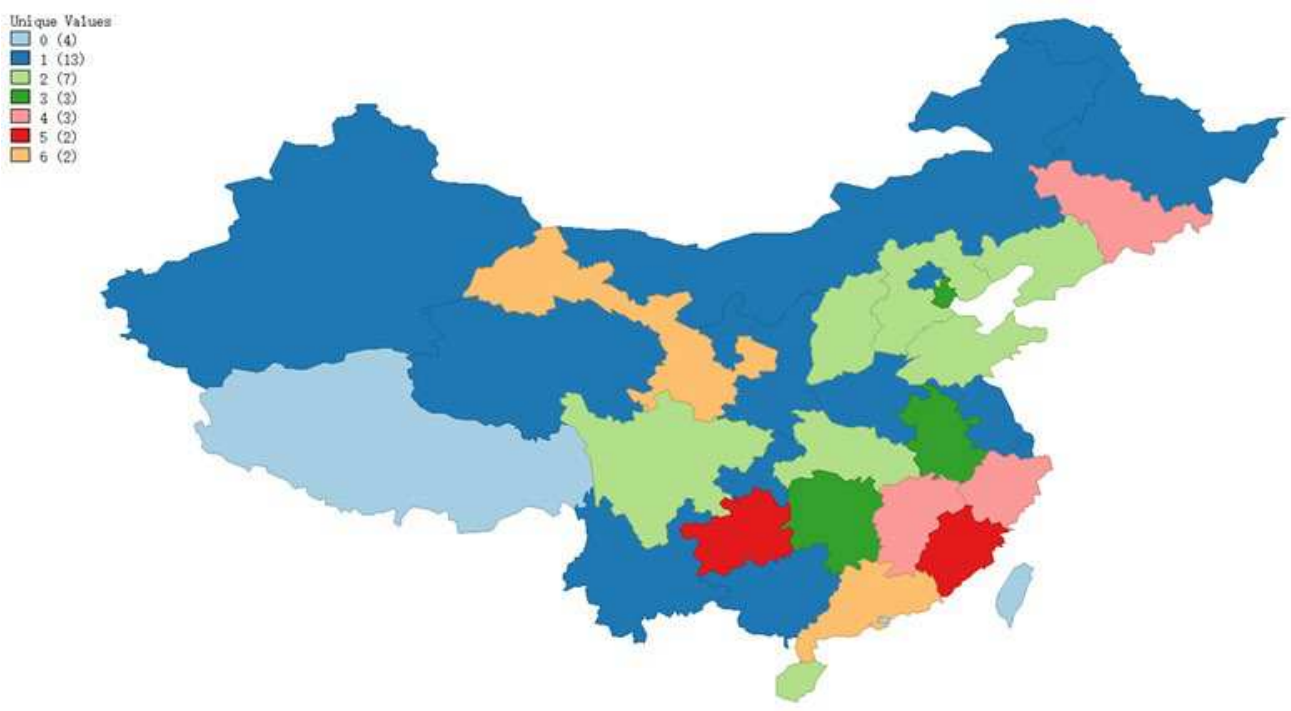

Fig. 7 Clustering results of the major influencing factors in 30 regions of China

Table 6. Number of occurrences of each influencing factor. 


\begin{tabular}{cccccccc}
\hline factors & A & B & C & D & E & F & 0 \\
\hline GDP & 13 & 9 & 5 & 2 & 1 & 0 & 0 \\
EI & 7 & 16 & 4 & 1 & 2 & 0 & 0 \\
CO & 3 & 1 & 9 & 9 & 4 & 4 & 0 \\
IS & 3 & 1 & 5 & 6 & 10 & 4 & 1 \\
HCL & 2 & 1 & 1 & 5 & 8 & 7 & 6 \\
UR & 2 & 2 & 6 & 7 & 5 & 4 & 4 \\
\hline
\end{tabular}

Table 6 lists the number of occurrences of each impact factor in the optimal model. The GDP was the most important factor for carbon emissions because it appeared as the primary factor in 13 regions in category A. Liu et al. (2012) reported that among these regions, Xinjiang and Inner Mongolia, with the potential for economic development, are the most important drivers of carbon emissions. The EI was the second most important factor affecting carbon emissions in the seven regions. However, in category B, the EI appeared 16 times while the GDP only appeared nine times, such that the EI is the extent of the impact of carbon emissions in second place. $\mathrm{CO}$ and IS together occupied the third position. The HCL and UR played an important role in two regions. Wang et al. (2019) found that economic growth, population growth, urbanization rate, fixed asset investment, and industrialization had a positive impact on $\mathrm{CO}_{2}$ emissions in Guangdong Province while the impact of the energy consumption structure and technological progress was negative. Finally, the HCL most frequently occurred in category 0 , indicating that this was least influential.

Table 7. Average value of each variable in each category.

\begin{tabular}{llllllll}
\hline Type & C & GDP & EI & CO & IS & HCL & UR \\
\hline Type-GDP & 6214.505 & 8730.081 & 1.675 & 283.867 & 0.446 & $\mathbf{9 1 9 3 . 0 0 3}$ & $\mathbf{0 . 4 9 4}$ \\
Type-EI & $\mathbf{1 1 7 5 0 . 8 2 0}$ & 12209.060 & $\mathbf{1 . 9 8 9}$ & 449.194 & 0.447 & 7319.805 & 0.423 \\
Type-CO & 5522.714 & 9036.451 & 1.294 & 264.283 & 0.455 & 9005.879 & 0.478 \\
Type-IS & 5780.977 & 10651.540 & 1.258 & 361.940 & $\mathbf{0 . 4 7 3}$ & 8758.818 & 0.473 \\
Type-HCL & 4798.802 & 7231.813 & 1.847 & 214.510 & 0.430 & 7418.591 & 0.446 \\
Type-UR & 7583.873 & $\mathbf{1 7 5 5 9 . 0 2 0}$ & 1.671 & $\mathbf{5 7 5 . 8 6 8}$ & 0.455 & 4969.045 & 0.314
\end{tabular}

The average value of each variable in each category is listed in Table 7. Type-GDP regions had the highest average HCL $(9,193.003)$ and UR (0.494) from 1995 to 2016. Type-EI regions had the highest average carbon emissions and highest EIs of 11750.820 and 1.989, respectively. We note that such areas should be the focus for management. A high energy consumption generates significant $\mathrm{CO}_{2}$ emissions while an effective reduction in the EI is key to a reduction in the $\mathrm{CO}_{2}$ emissions. Type-IS regions had the highest percentage of IS. Type-UR had the highest average GDP (17 559.020) and CO (575.868). In these areas, urban development drives residents to buy more cars, which is also the 


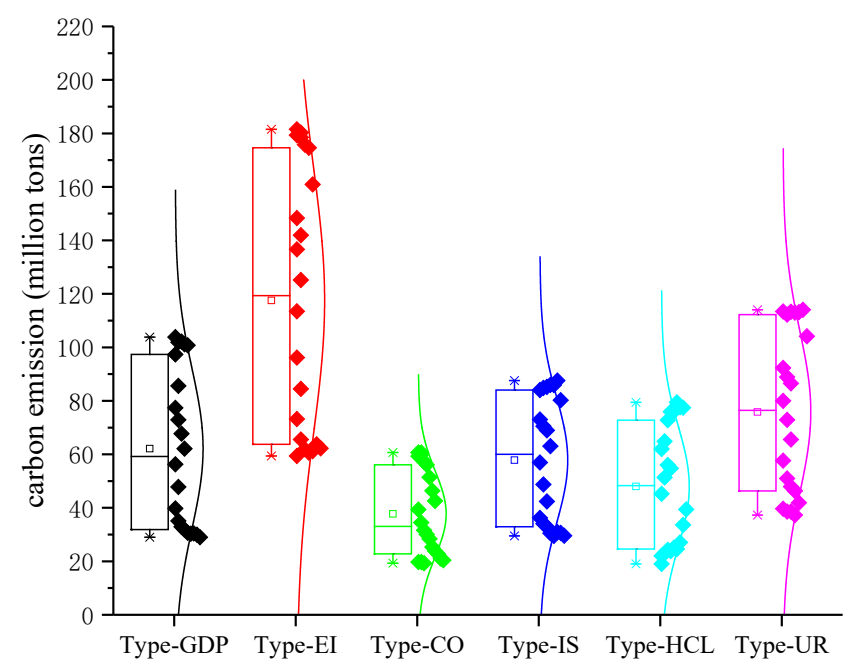
the figure include four values, i.e., the average value (shown by the small white square), the median value (shown by the white bar), the $75^{\text {th }}$ percentile (shown by the top edge), and the $25^{\text {th }}$ percentile (shown by the bottom edge).

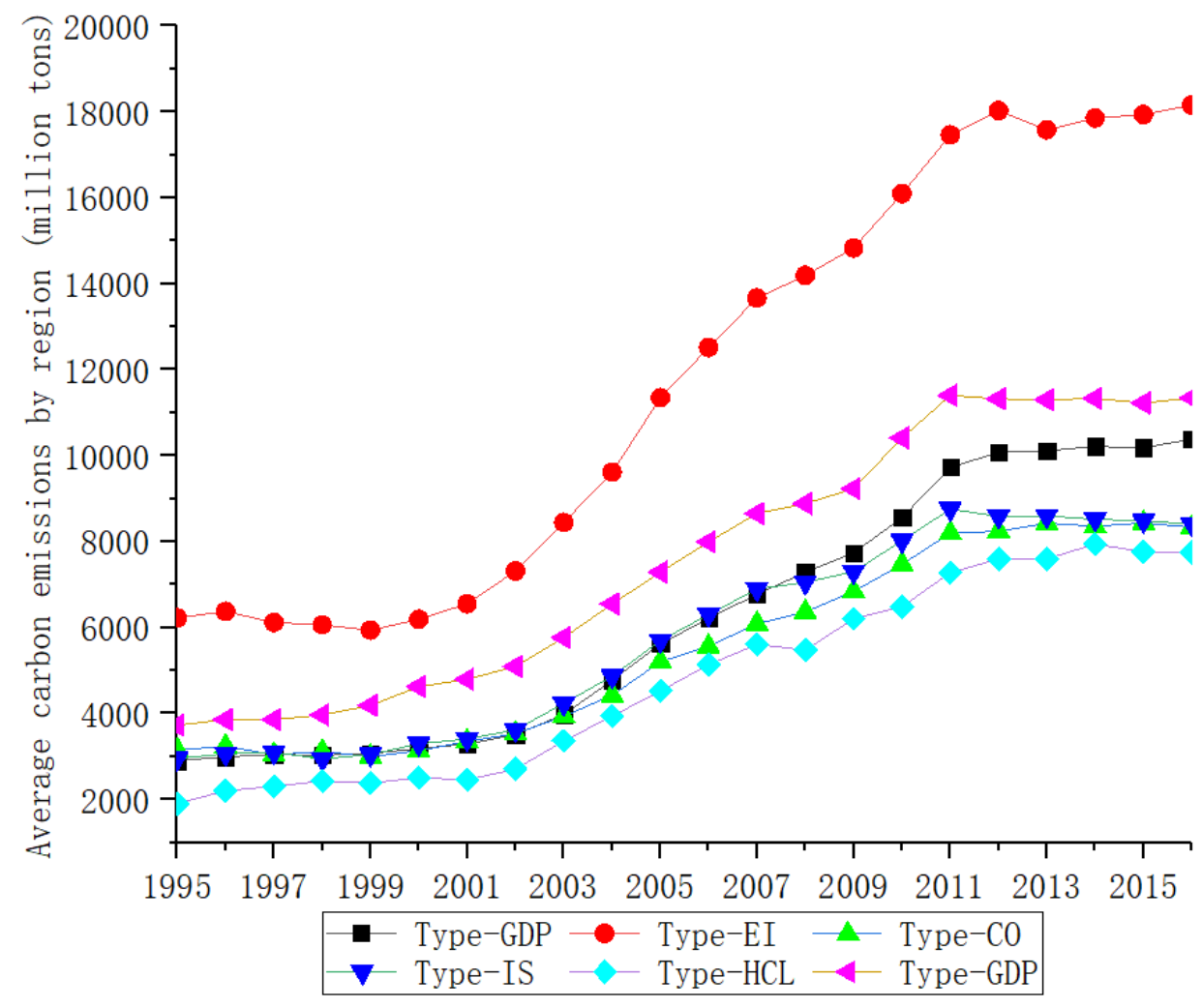

Fig. 9. Average carbon emissions in each category of region. 
Figure 8 shows the detailed distribution of carbon emissions in the six regions from 1995 to 2016. Figure 9 depicts the average carbon emissions in each type of region from 1995-2016. The annual average growth rates of Type-GDP, Type-EI, Type-CO, Type-IS, Type-HCL, and Type-UR were 6.26, $5.23,4.74,5.10,6.91$, and $5.44 \%$, respectively. The average carbon emissions in each region showed a steady development trend since 2011. The main reason for this phenomenon is likely the government's effective implementation of emissions reduction policies. According to the average carbon emissions of each region, the order of the average carbon emissions from high to low was Type-EI, Type-UR, Type-GDP, Type-IS, Type-CO, and Type-HCL.

\subsection{Decoupling analysis}

Based on the cluster classification results in the previous section, the decoupling index between the carbon emissions and economic growth in the six regions of the country was built, which analyzed the internal relationship between the carbon emissions and economic growth, based on which we proposed appropriate energy-saving and emissions reduction measures for each region.

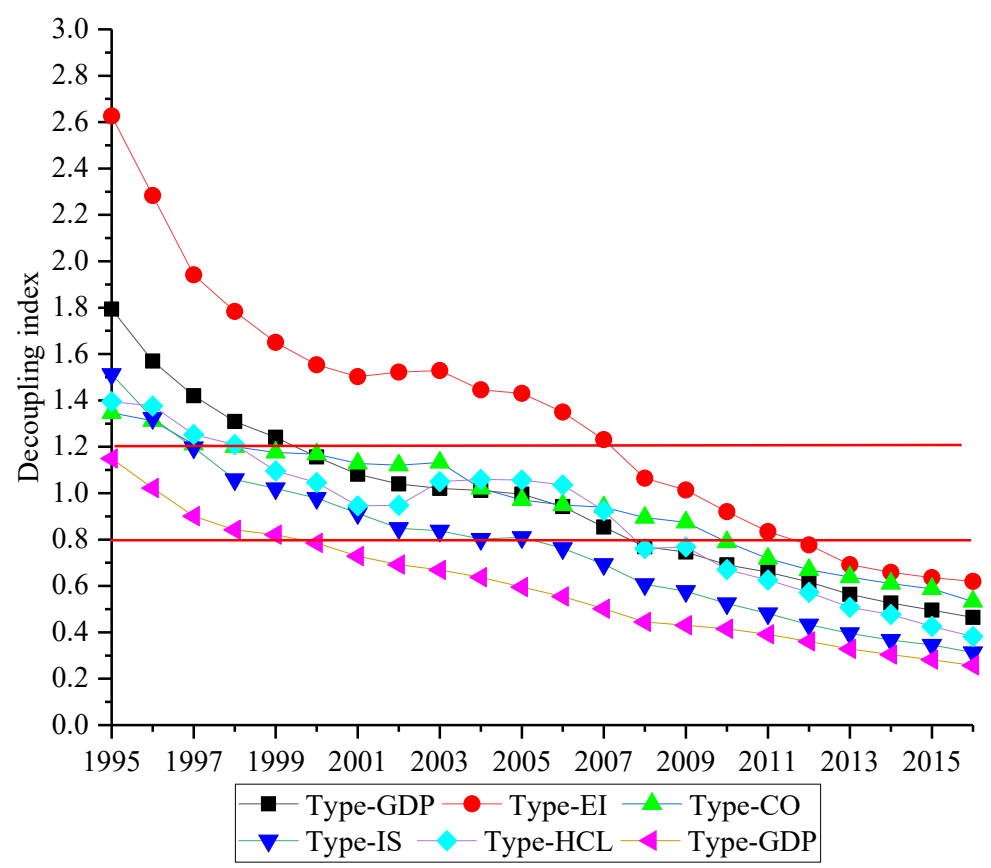

Fig. 10 Decoupling index results for the six types of regions.

Figure 10 indicates that the decoupling relationship between the carbon emissions and economic growth in the six types of regions had a downward trend. Except for Type-EI, the other five types of regions entered an expansive coupling and weak decoupling state since the enactment of the $10^{\text {th }}$ Five-Year Plan (2001-2005), indicating that since then the country has increased its efforts in energy conservation and emissions reduction measures. However, while the decoupling index of EI-based regions decreased, the decoupling index entered a weak decoupling state after 2012. The economic growth rate was slightly higher than the growth rate of carbon emissions, indicating that the regions were gradually changing their manners of promoting economic growth at the expense of energy consumption, gradually achieving the goals of energy conservation and emissions reduction. 
Moreover, the decoupling coefficient represented by Type-EI had the fastest and largest decline from 1995 to 2016 (Fig. 10). This was mainly because energy is the main source of $\mathrm{CO}_{2}$, which is based on the EI. The main areas belonging to Type-EI were Liaoning, Hebei, Shanxi, Shandong, Hubei, and other high-energy energy areas, which are characterized by high pollution and energy consumption. Emission measures have impacted regions dominated by EI. At the same time, the decoupling index of Type-EI for carbon emissions and economic growth showed the largest decline of $6.65 \%$; therefore, this is the most effective technique to realize energy savings and emissions reduction by controlling the EI. Overall, the decoupling index of each region showed a relatively flat trend over time, which represents a weak decoupling state. The reason for such a weak decoupling may be that under the country's strong governmental macro-control, each region is actively achieving government calls for energy conservation and emissions reductions by adopting a series of emissions reduction measures and promoting economic growth.

Interestingly, the HCL regions were weakly decoupled after 2008. Fujian and Guizhou experienced a decline in volatility. The average annual growth rate of HCL in Fujian before 1995-2001 was 7.92 \%; from 2001 to 2004, the average annual growth rate was $8.80 \%$. From 1995 to 2001, the carbon emissions growth rate of the HCL regions was $4.37 \%$ and the GDP growth rate was $11.35 \%$, whereas the carbon emissions growth rate from 2001 to 2004 was $16.99 \%$ and the GDP growth rate was $12.64 \%$. Cities in the HCL regions did not strictly implement the relevant national energy-saving and emissions reduction policies during the "Tenth Five-Year Plan" period, resulting in the rapid growth of carbon emissions.

In the IS and GDP regions, the decoupling coefficient of carbon emissions and the GDP showed a gradual decrease, indicating that these regions had actively been achieving national energy-saving and emissions reduction targets, resulting in a weak decoupling between carbon emissions and the GDP in 2010. In regions where CO was the main driving force, the decoupling index of carbon emissions and economic growth tended to be flat. The government encourages the purchase of new energy vehicles to achieve energy conservation and emissions reduction goals.

In UR regions, such as Guangdong and Gansu, the decoupling relationship between carbon emissions and economic growth has been weakly decoupled since 2000. However, the average carbon emissions of the UR region were 75.83873 million tons, ranking second among the six regions, while the economic growth was highest, reaching 17559.02 ten thousand yuan, representing rapid economic growth at the cost of high energy consumption. Since 1995, the decoupling coefficient of the UR regions has been 1.15 , which has decreased annually by $6.87 \%$, resulting in the smallest carbon emissions and elasticity in the economic growth in these regions.

If China's "extensive" development method does not undergo a fundamental change, its development process will not be able to effectively decouple from carbon emissions. Considering the coal industry's declining trend and the continued decrease in coal prices, coal may be the primary choice for energy generation in some industries, such that the energy consumption structure dominated by coal is difficult to change through market choices in the short term.

\section{Conclusions and policy proposals}

To achieve green economic development, the Chinese government has always coordinated the relationship between economic growth and environmental protection, seeking a pathway to develop a 
low-carbon economy. We used symbolic regression and automatic identification and search methods to explore the factors affecting carbon emissions, including the GDP, EI, UR, IS, HCL, and CO in 30 regions in China. We used 22-year data resources from 1995 to 2016 . We conclude that the factors affecting carbon emissions vary by region. Accounting for the factors that have the greatest impact on carbon emissions, we divided the country into six areas: Type-GDP, Type-EI, Type-CO, Type-IS, Type-HCL, and Type-UR.

From 1995 to 2016, the growth rate of national carbon emissions was $5.63 \%$; there were 13 regions with GDP as the main factor, including Beijing, Inner Mongolia, Heilongjiang, Jiangsu, Henan, Shaanxi, Qinghai, Ningxia, Chongqing, Shanghai, Guangxi, Yunnan, and Xinjiang. Seven regions were dominated by the EI, including Liaoning, Shandong, Hainan, Hebei, Hubei, Sichuan, and Shanxi. We further used the Tapio decoupling model to analyze the decoupling coefficient between carbon emissions and economic growth in the six classified areas. The annual average growth rate of carbon emissions for the Type-GDP, Type-EI, Type-CO, Type-IS, Type-HCL, and Type-UR areas were 6.26, $5.23,4.74,5.10,6.91$, and $5.44 \%$, respectively. The decoupling index showed a downward trend for each region, among which the EI region had the highest carbon emissions; its decoupling index showed the largest decline.

As the influencing factors had a significantly differing impact on the carbon emissions in the different regions, we proposed a combination of the regional characteristics and resource endowments to develop differentiated carbon emissions reduction strategies to promote the development of a low-carbon economy. The following suggestions can be made based on our results and analysis.

First, differentiated regional emissions reduction targets based on local conditions should be developed. Therefore, the setting of emissions reduction targets and the formulation of policies should be determined according to the actual conditions of each region and not be unified. The focus should be on areas with high carbon emissions, such as Type-EI areas, while areas with moderate carbon emission levels should be regularly monitored, such as Type-GDP and Type-UR areas. Areas with low carbon emissions can focus on economic development, such as Type-CO and Type-HCL areas.

Second, technological innovation should be encouraged, with the promotion of energy-savings and emissions reduction technologies. The government should increase investments in advanced energy-saving technologies, such that new technologies can be applied to production in a timely and effective manner, thereby reducing unit carbon emissions, making full use of high-tech and advanced environmental protection technologies to upgrade and optimize traditional industries. The research and development of new energy sources, such as wind and solar energy, has improved the utilization efficiency of new energy sources and reduced the use of fossil energy, thus encouraging a low-carbon economy. The government should therefore encourage companies to use new energy sources and provide preferential policies.

Third, low-carbon industries should actively be developed, industrial structures optimized, and a low-carbon economy developed. Examples include Jiangxi, Zhejiang, and Jilin. First, for traditional high-energy-consuming industries, we must not only eliminate the backward production capacity, but also carry out low-carbon environmental protection transformation and upgrades. For example, through technology upgrades, the use of clean and renewable energy can be encouraged; high-carbon emissions industries should be supervised and managed, energy-saving emissions reduction tasks determined, and 
low-carbon economic development achieved. Moreover, new industrialization and environmentally friendly developments of advanced manufacturing and high-technology industries through preferential policies from the government should be achieved. Finally, the government should actively promote the development of tertiary industries and the economy, thereby reducing carbon pollution during the urbanization process.

Fourth, during urbanization, the consumption levels of residents should be reasonably controlled. High-level consumption leads to an increase in carbon emissions. To raise resident awareness of the benefits of low carbon emissions, we recommend that the government introduces relevant policies to increase low-carbon environmental protection projects and rationally allocate resident spending power, particularly in Fujian and Guizhou. The government should also encourage urban residents to start businesses, continuously improve their independent innovation capabilities, and promote the regional GDP. At the same time, especially in Guangdong and Gansu, the urban population growth rate has significantly increased, which has promoted the large-scale migration of rural populations to cities and reduced regional carbon emissions.

Fifth, although $\mathrm{CO}$ was not the most important factor, it was still relevant in some regions, indicating that this factor cannot be ignored. The government should encourage the development of environmentally friendly and energy-saving power batteries. For example, the active exploration of new electric vehicles based on hydrogen fuel cell technology is expected to achieve zero emissions. In contrast, the government should vigorously promote the implementation of electric buses to gradually replace traditional fuel buses and encourage residents to buy new electric vehicles to achieve maximum carbon emissions reductions.

\section{Ethical Approval: Not applicable}

\section{Consent to Participate: Not applicable}

\section{Consent to Publish: Not applicable}

Author contributions: All authors contributed to the study conception and design. Material preparation, data collection and analysis were performed by [Haiying Liu] and [Zhiqun Zhang]. The first draft of the manuscript was written by [Zhiqun Zhang] and all authors commented on previous versions of the manuscript. All authors read and approved the final manuscript.

Funding: This work was supported by [National Natural Science Foundation of China] (Grant numbers [20BJY102]

\section{Competing Interests: Not applicable}

Availability of data and materials: The datasets generated and/or analysed during the current study are not publicly available due [Part of the data comes from research] but are available from the corresponding author on reasonable request.

\section{References}

Bartosz, S., Jarosław, G., 2016. Application of Selected Methods of Artificial Intelligence to Activated 
Sludge Settleability Predictions. Polish Journal of Environmental Studies 25(4), 1709-1714. Bellocchi, S., Gambini, M., Manno, M., et al., 2018. Positive interactions between electric vehicles and renewable energy sources in CO2-reduced energy scenarios: The Italian case. Energy 161, 172-182.

Can, B., Heavy, C., 2011. Comparison of experimental designs for simulation-based symbolic regression of manufacturing systems. Comput. Ind. Eng. 61(3), 447-462.

Dong, X.Y., Hao, Y., 2018. Would income inequality affect electricity consumption? Evidence from China. Energy 142, 215-227.

Fan, J.L., Cao, Z., Zhang, X., Wang, J.D., Zhang, M., 2019. Comparative study on the influence of final use structure on carbon emissions in the Beijing-Tianjin-Hebei region. Sci. Total Environ. 668, 271-282.

Huang, J.B., Liu, C.H., Chen, S.X., Huang, X., Hao, Y., 2019. The convergence characteristics of China's carbon intensity: Evidence from a dynamic spatial panel approach. Sci. Total Environ. 668, 685-695.

IPCC, 2006. Greenhouse Gas Inventory: IPCC Guidelines for National Greenhouse Gas Inventories. United Kingdom Meteorological Office, Bracknell, England.

Jiang, J.J., Ye, B., Xie, D.J., Tang, J., 2017. Provincial-level carbon emission drivers and emission reduction strategies in China: Combining multi-layer LMDI decomposition with hierarchical clustering. J. Clean. Prod. 169, 178-190.

Jin, Y.C., Bernhard, S., 2008. Pareto-Based Multi objective Machine Learning: An Overview and Case Studies. IEEE T. Syst. Man. Cy. C 38(3), 397-415.

Khu, S.T., Liong, S.Y., Babovic, V., Madsen, H., Muttil, N., 2001. Genetic programming and its application in real-time runoff forecasting. J. Am. Water Res. Assoc. 37(2), 439-451.

Freitas, L.C., Kaneko, S., 2011. Decomposing the decoupling of $\mathrm{CO}_{2}$ emissions and economic growth in Brazil. Ecol Econ 70, 1459-1469.

Lee, K., Oh, W., 2006. Analysis of $\mathrm{CO}_{2}$ emissions in APEC countries: A time-series and a cross-sectional decomposition using the log mean Divisia method. Energy Policy 34(17), 2779-2787.

Li, B., Yao, R., 2009. Urbanisation and its impact on building energy consumption and efficiency in China. Renew. Energy 34 (9), 1994-1998.

Li, S., Zhou, C., 2019. What are the impacts of demographic structure on $\mathrm{CO}_{2}$ emissions? A regional analysis in China via heterogeneous panel estimates. Sci. Total Environ. 650, 2021-2031.

Lin, B.Q., Benjamin, N.I., 2019. Determinants of industrial carbon dioxide emissions growth in Shanghai: A quantile analysis. J. Clean. Prod. 217, 776-786.

Liu, L., Wang, K., Wang, S.S., Zhang, R.Q., Tang, X.Y., 2019. Exploring the Driving Forces and Reduction Potential of Industrial Energy-Related $\mathrm{CO}_{2}$ Emissions during 2001-2030: A Case Study for Henan Province, China. Sustainability 11(4).

Liu, L.C., Wu, G., Wang, J.N., 2011. China's carbon emissions from urban and rural households during 1992-2007. J. Clean. Prod. 19(15), 1754-1762.

Liu, Z., Geng, Y., Lindner, S., 2012. Uncovering China's greenhouse gas emission from regional and sectoral perspectives. Energy 45(1), 1059-1068.

Luo, H., Li, L., Lei, Y.L., Wu, S.M., Yan, D., Fu, X.S., Luo, X.M., Wu, L.K.., 2020. Decoupling analysis between economic growth and resources environment in Central Plains Urban Agglomeration. Sci. Total Environ. 752.

O'Reilly, U.M., 2014. Genetic Programming II: Automatic Discovery of Reusable Programs. Artific. Life 1(4), 439-441. 
Pan, X.F., Uddin, M.K., Ai, B.W., Pan, X.Y., Saima, U., 2019. Influential factors of carbon emissions intensity in OECD countries: Evidence from symbolic regression. J. Clean. Prod. 220, 1194-1201.

Quan, C.G., Cheng, X.J., Yu, S.S., Ye, X., 2020. Analysis on the influencing factors of carbon emission in China's logistics industry based on LMDI method. Sci. Total Environ. 734.

Schandl, H., Hatfield-Dodds, S., Wiedmann, T., Geschke, A., Cai, Y.Y., West, J., Newth, D., Baynes, T., Lenzen, M., Owen, A., 2016. Decoupling global environmental pressure and economic growth: scenarios for energy use, materials use and carbon emissions. J. Clean. Prod. 132, 45-56.

Schmidt, M., Lipson, H., 2009. Distilling Free-Form Natural Laws from Experimental Data. Science, 324(5923), 81-85.

Shahbaz, M., Loganathan, N., Muzaffar, A.Z., Ahmed K., Jabran, M.A., 2016. How urbanization affects CO2 emissions in Malaysia? The application of STIRPAT model. Renew. Sustain. Energy Rev. 57, 83-93.

Shen, L., Wu, Y., Lou, Y., Zeng, D., Shuai, C., Song, X., 2018. What drives the carbon emission in the Chinese cities? - a case of pilot low carbon city of Beijing. J. Clean. Prod. 174, 343-354.

Shi, Q., Chen, J., Shen, L., 2017. Driving factors of the changes in the carbon emissions in the Chinese construction industry. J. Clean. Prod. 166, 615-627.

Shuai, C.Y., Chen, X., Wu, Y., Tan, Y.T., Zhang, Y., Shen, L.Y., 2018. Identifying the key impact factors of carbon emission in China: Results from a largely expanded pool of potential impact factors. J. Clean. Prod. 175, 612-623.

Song, M., Wu, J., Song, M.R., Zhang, L.Y., Zhu, Y.X., 2020. Spatiotemporal regularity and spillover effects of carbon emission intensity in China's Bohai Economic Rim. Sci. Total Environ. 740.

Vladislavleva, E.J., Smits, G.F., Hertog, D., 2009. Order of nonlinearity as a complexity measure for models generated by symbolic regression via Pareto genetic programming. IEEE T. Evolut. Comput. 13(2), 333-349.

Wang, C., Zhang, X., Wang, F., Lei, J., Zhang, L., 2015. Decomposition of energy-related carbon emissions in Xinjiang and relative mitigation policy recommendations. Front. Earth Sci. 9(1), 65-76.

Wang, P., Wu, W.S., Zhu, B.Z., Wie, Y.M., 2013. Examining the impact factors of energy-related $\mathrm{CO}_{2}$ emissions using the STIRPAT model in Guangdong Province, China. Appl. Energy 106, 65-71.

Wang, S.J., Wang, J.Y., Li, S.J., 2019. Socioeconomic driving forces and scenario simulation of $\mathrm{CO}_{2}$ emissions for a fast-developing region in China. J. Clean. Prod. 216, 217-229.

Wen, L., Ma, Z.Y., Li, Y., Li, Q., 2017. An investigation and forecast on $\mathrm{CO}_{2}$ emission of China: Case studies of Beijing and Tianjin. Environ. Eng. Res. 22(4), 407-416.

Wen, L., Li, Q., Li, Y., 2018. Carbon Emission and Economic Growth Model of Beijing Based on Symbolic Regression. Pol. J. Environ. Stud. 27(1), 365-372.

Wu, C.H., Chou, H.J., Su, W.H., 2008. Direct transformation of coordinates for GPS positioning using the techniques of genetic programming and symbolic regression. Eng. Appl. Artif. Int. 21(8), 13471359.

Wu, Y., Tam, V.W.Y., Shuai, C.Y., Shen, L.Y., Zhang, Y., Liao, S.J., 2019. Decoupling China's economic growth from carbon emissions: Empirical studies from 30 Chinese provinces (2001-2015). Sci. Total Environ. 656, 576-588.

Xie, P.J.; Yang, F.; Mu, Z.W.; Gao, S.S., 2020. Influencing factors of the decoupling relationship between $\mathrm{CO}_{2}$ emission and economic development in China's power industry. Energy 209, .

Yang, G.F., Li, W.L., Wang, J.L., Zhang, D.Q., 2016. A comparative study on the influential factors of China's Provincial energy intensity. Energy Policy 88, 74-85. 

Policy 82, 48-61.

560 Yang, L., Yang, Y., Zhang, X., Tang, K., 2018. Whether China's industrial sectors make efforts to 561 reduce $\mathrm{CO}_{2}$ emissions from production? A decomposed decoupling analysis. Energy 160, 796-809.

562 Yu, Y.D., Zhou, L., Zhou, W.J., Ren, H.T., Kharrazi, A., Ma, T.J., Zhu, B., 2017. Decoupling 563 environmental pressure from economic growth on city level: The Case Study of Chongqing in China. 564 Ecol. Indic. 75, 27-35.

565 Zhang, C.G., Lin, Y., 2012. Panel estimation for urbanization, energy consumption and $\mathrm{CO}_{2}$ emissions: 566 A regional analysis in China. Energy Policy 49, 488-498.

567 Zhang, Y.J., Da, Y.B., 2015. The decomposition of energy-related carbon emission and its decoupling 568 with economic growth in China. Renew. Sust. Energ. Rev. 41, 1255-1266.

569 Zhang, L., Chen, D., Peng, S., et al., 2020. Carbon emissions in the transportation sector of Yangtze 570 River Economic Belt: decoupling drivers and inequality. Environ. Sci. Poll. Res. 27(17), 21098-21108. 
Figures

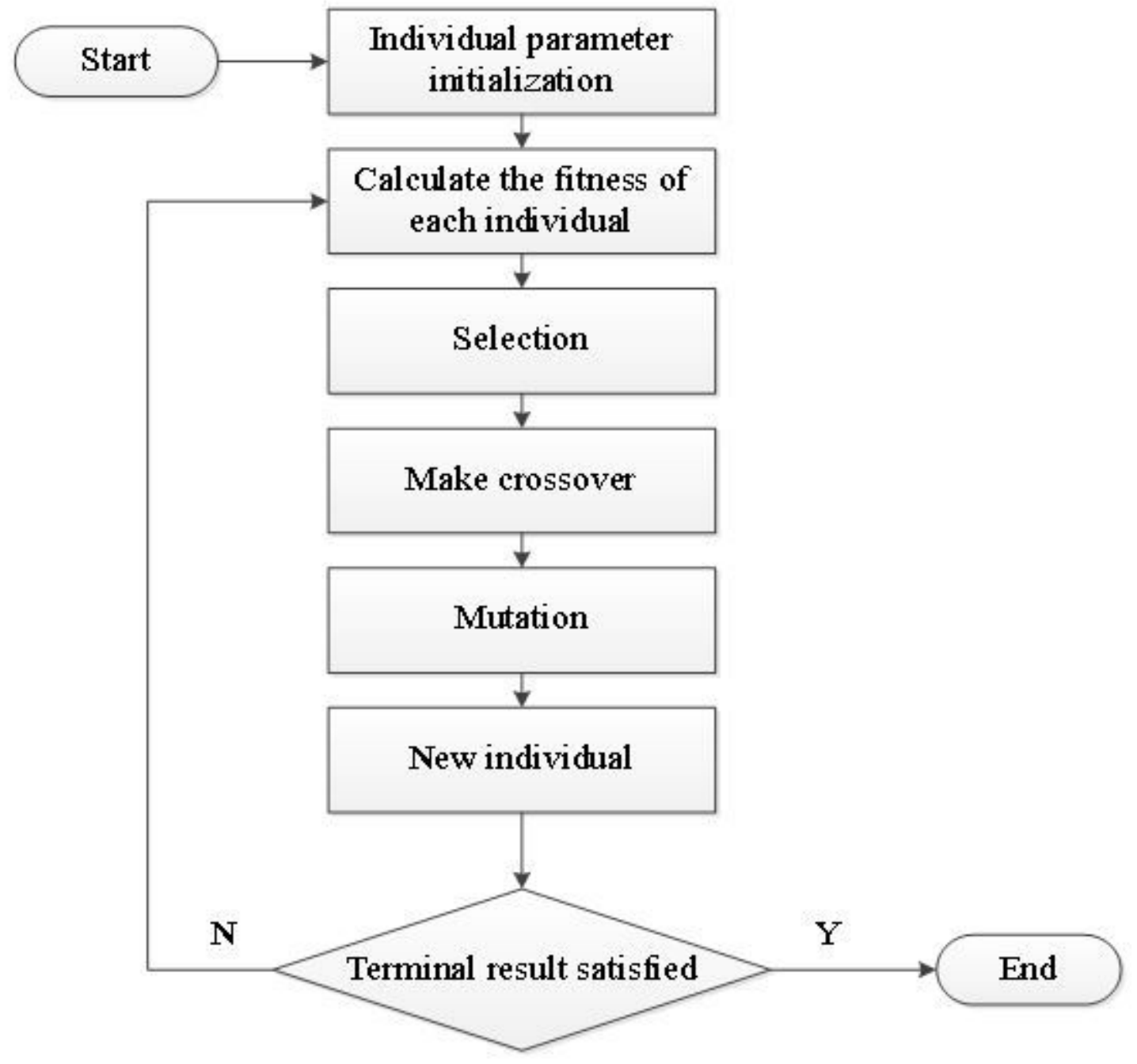

Figure 1

Genetic planning of symbolic regression. 


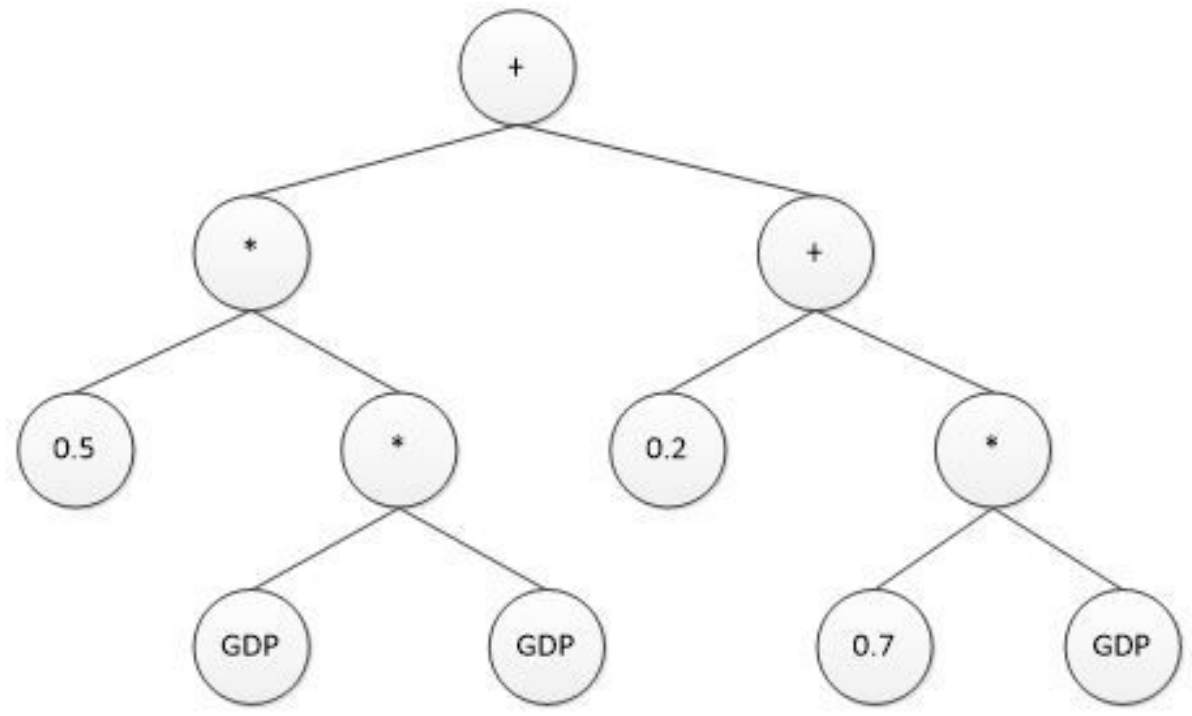

Figure 2

Example of a tree structure in symbolic regression for the expression 0.5 * GDP $2+0.7$ * GDP +0.2 .

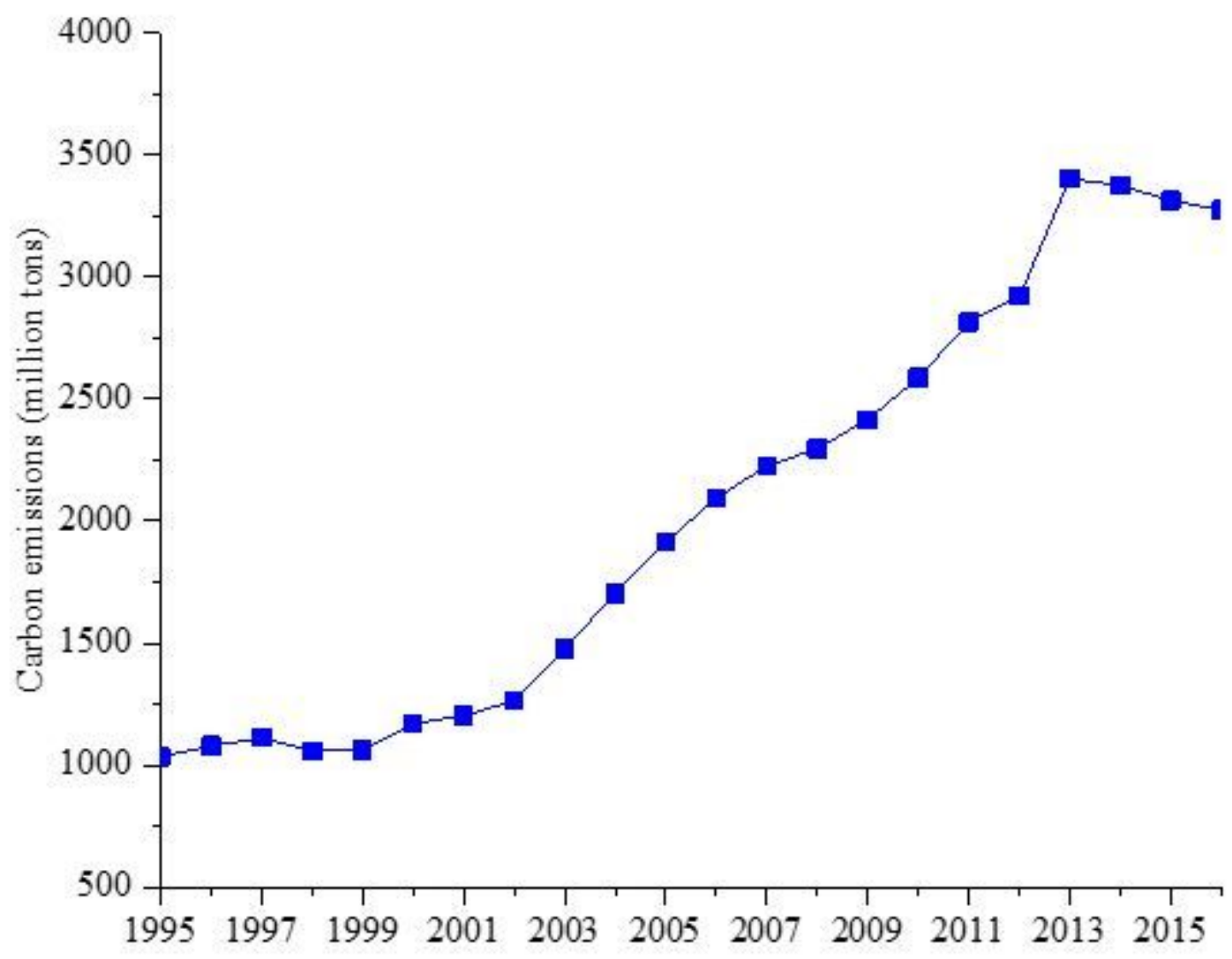

Figure 3

Changes in the carbon emissions in the 30 regions of China. 


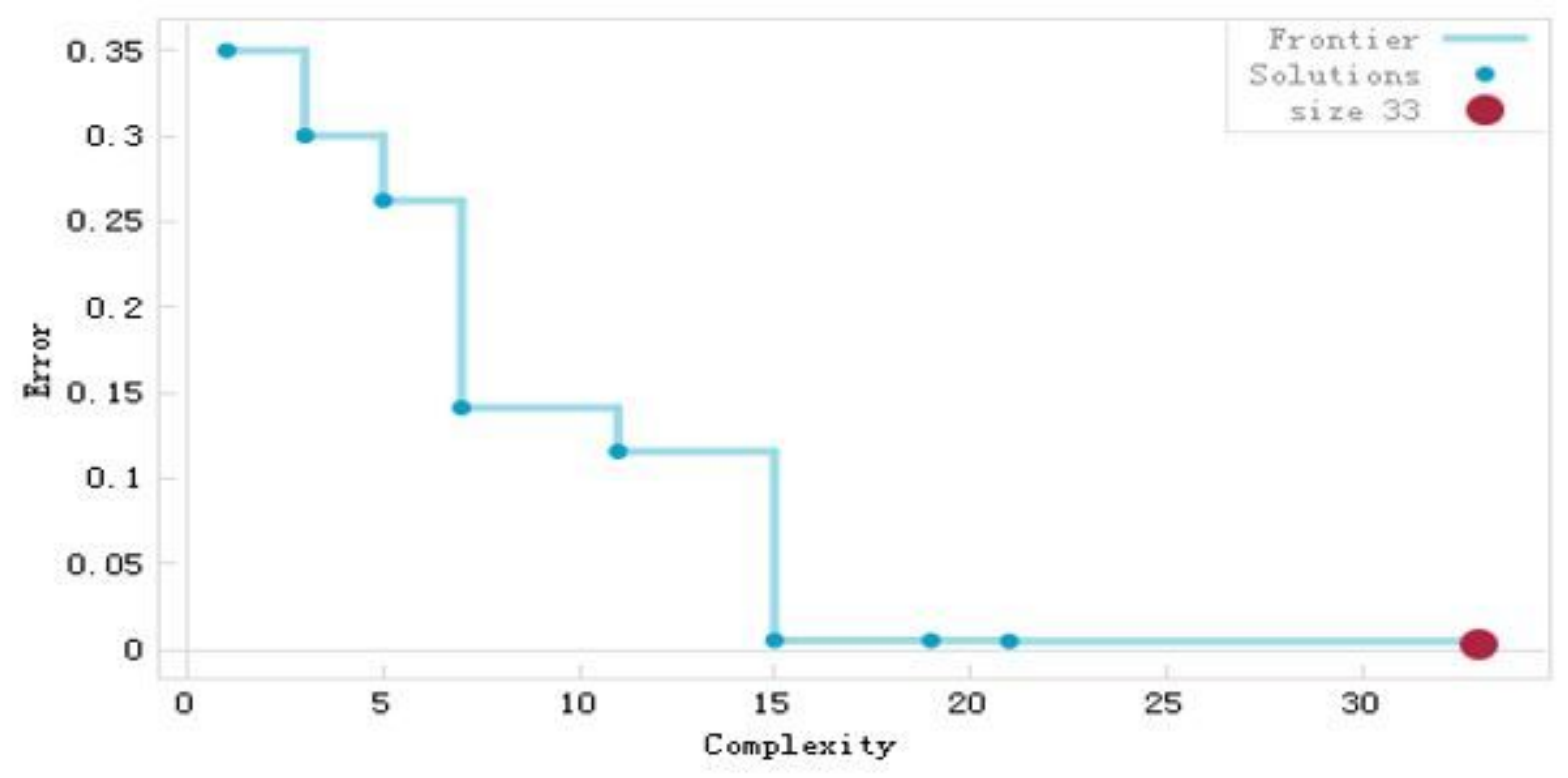

Figure 4

Pareto front in Chongqing.

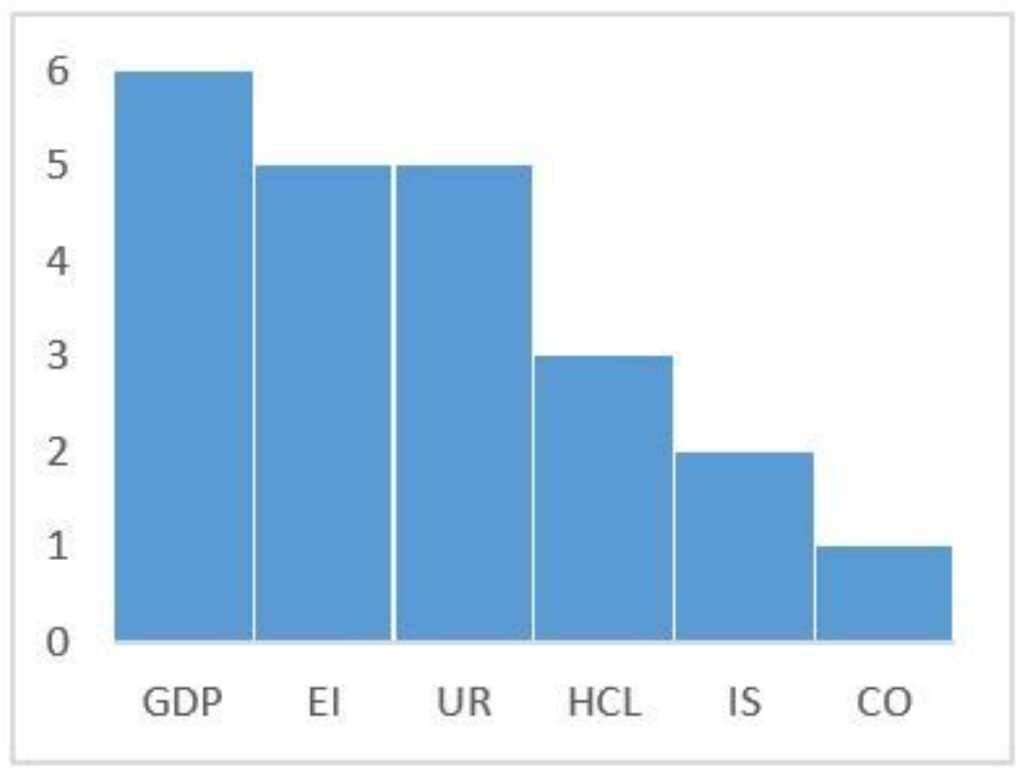

Figure 5

Number of models each variable appears in for Chongqing. 


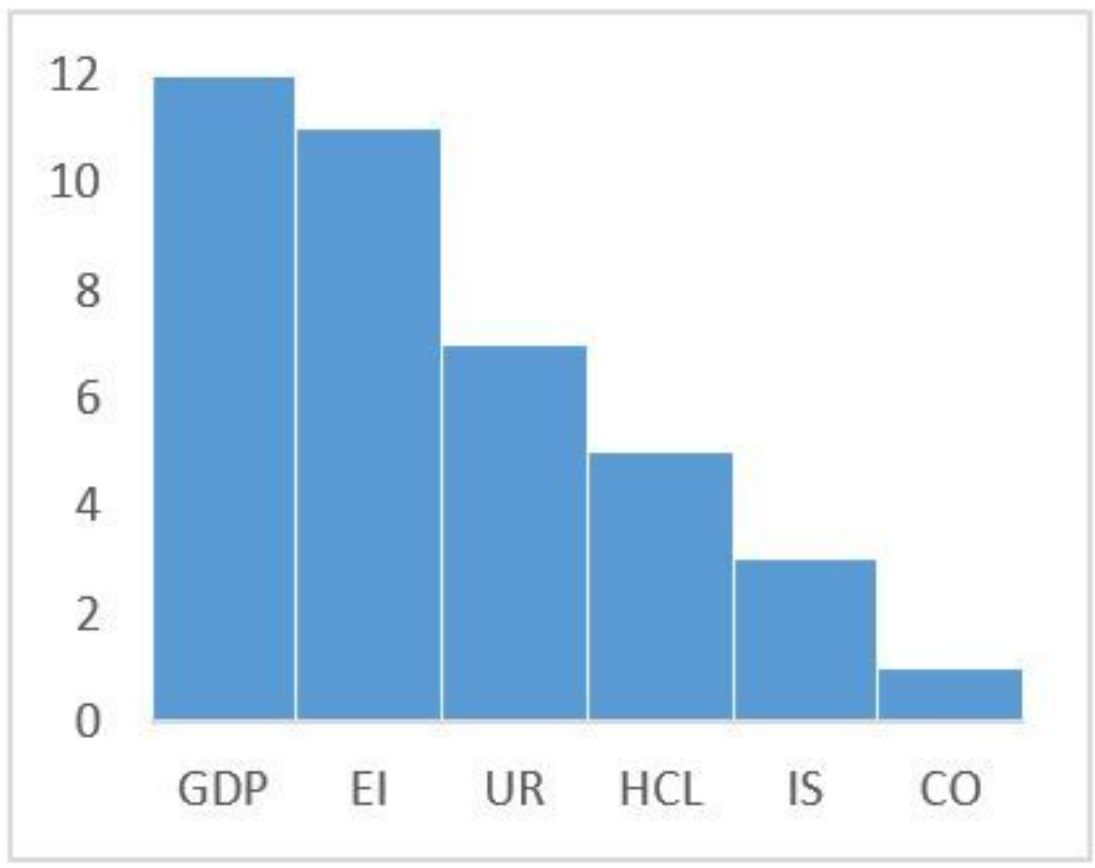

Figure 6

Number of occurrences of each variable in Chongqing (across all models).

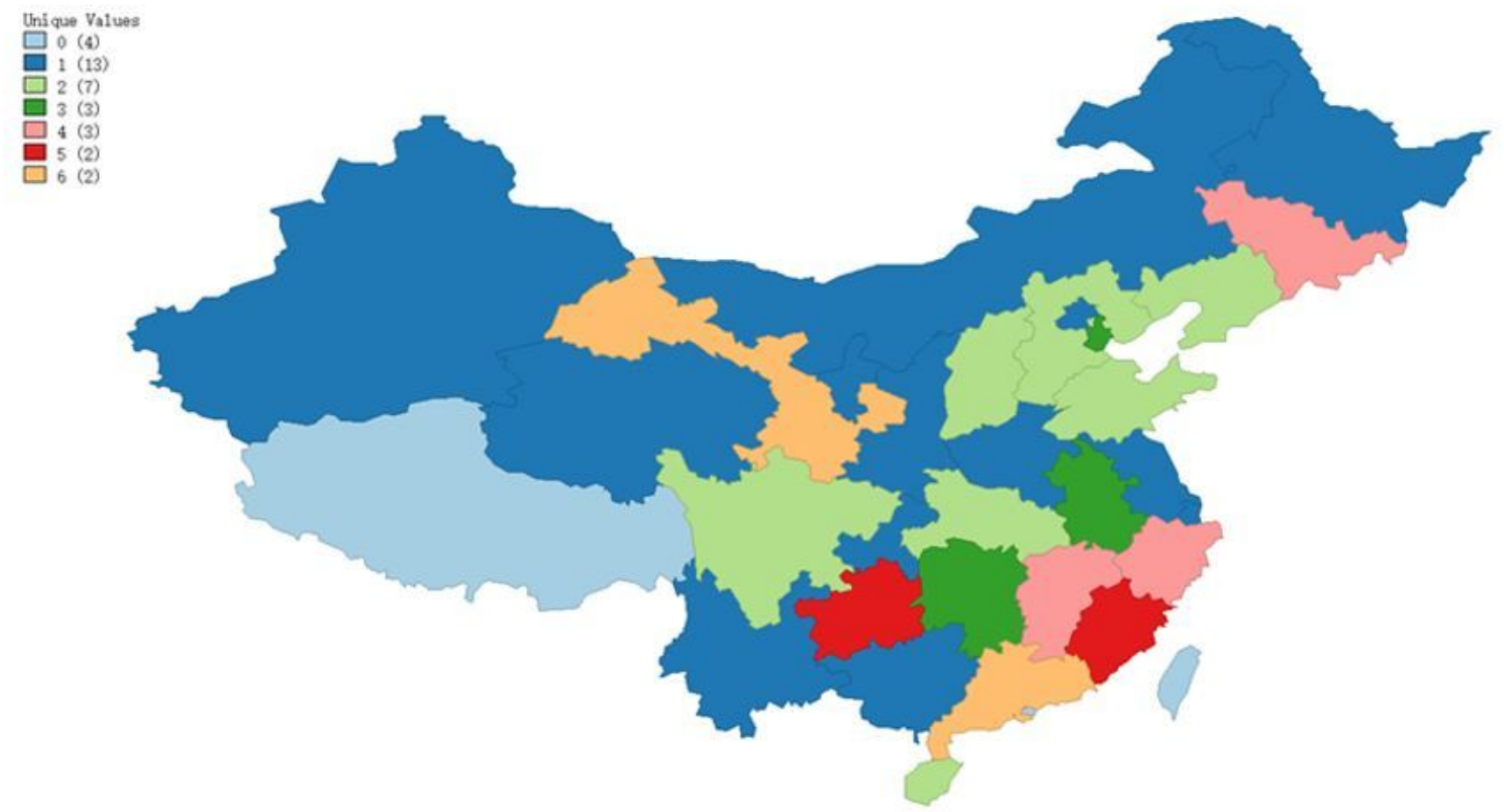

Figure 7

Clustering results of the major influencing factors in 30 regions of China. Note: The designations employed and the presentation of the material on this map do not imply the expression of any opinion whatsoever on the part of Research Square concerning the legal status of any country, territory, city or 
area or of its authorities, or concerning the delimitation of its frontiers or boundaries. This map has been provided by the authors.

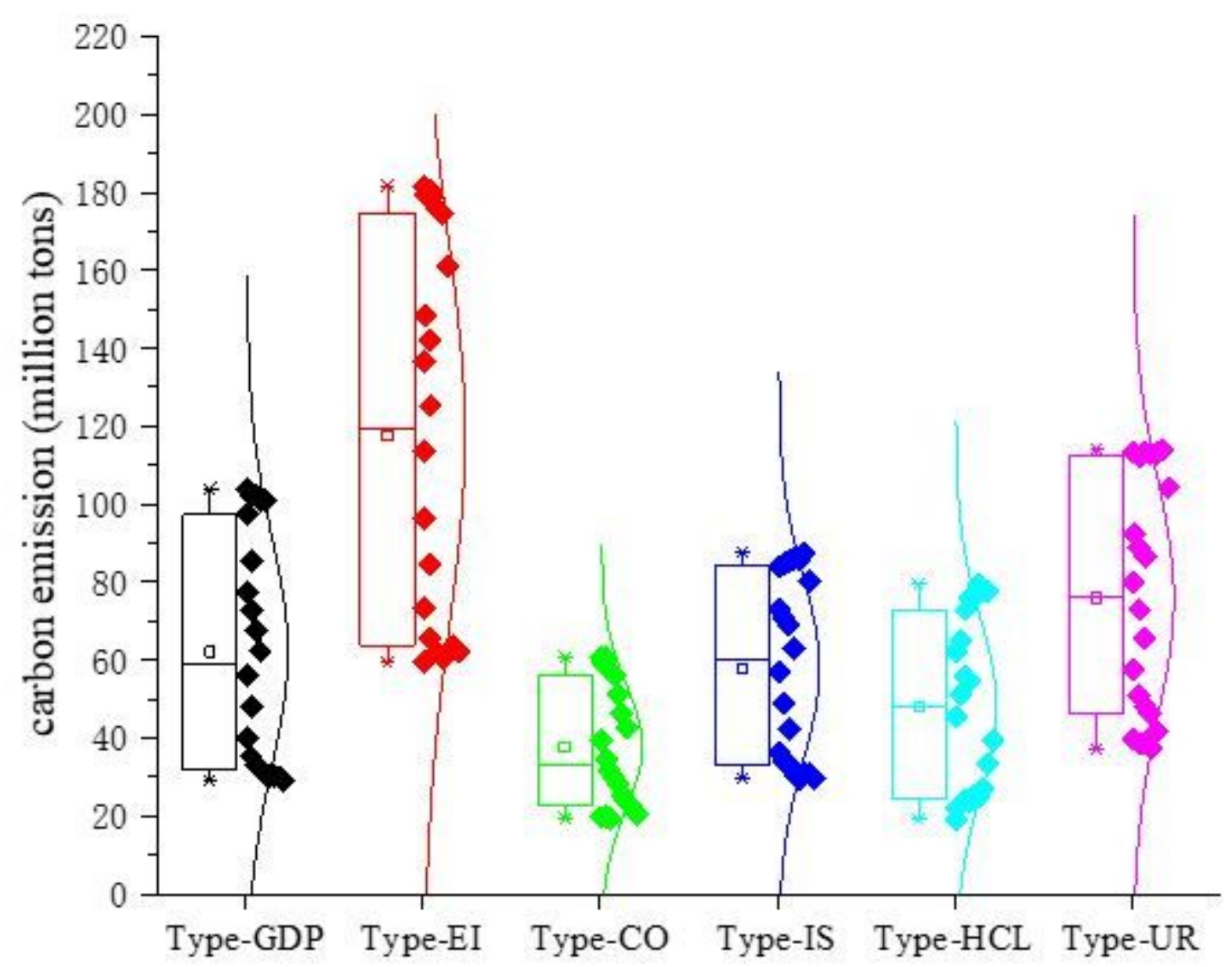

Figure 8

Scatter box plot for Type-GDP, Type-El, Type-CO, Type-IS, Type-HCL, and Type-UR. Note: the boxes in the figure include four values, i.e., the average value (shown by the small white square), the median value (shown by the white bar), the 75th percentile (shown by the top edge), and the 25th percentile (shown by the bottom edge). 


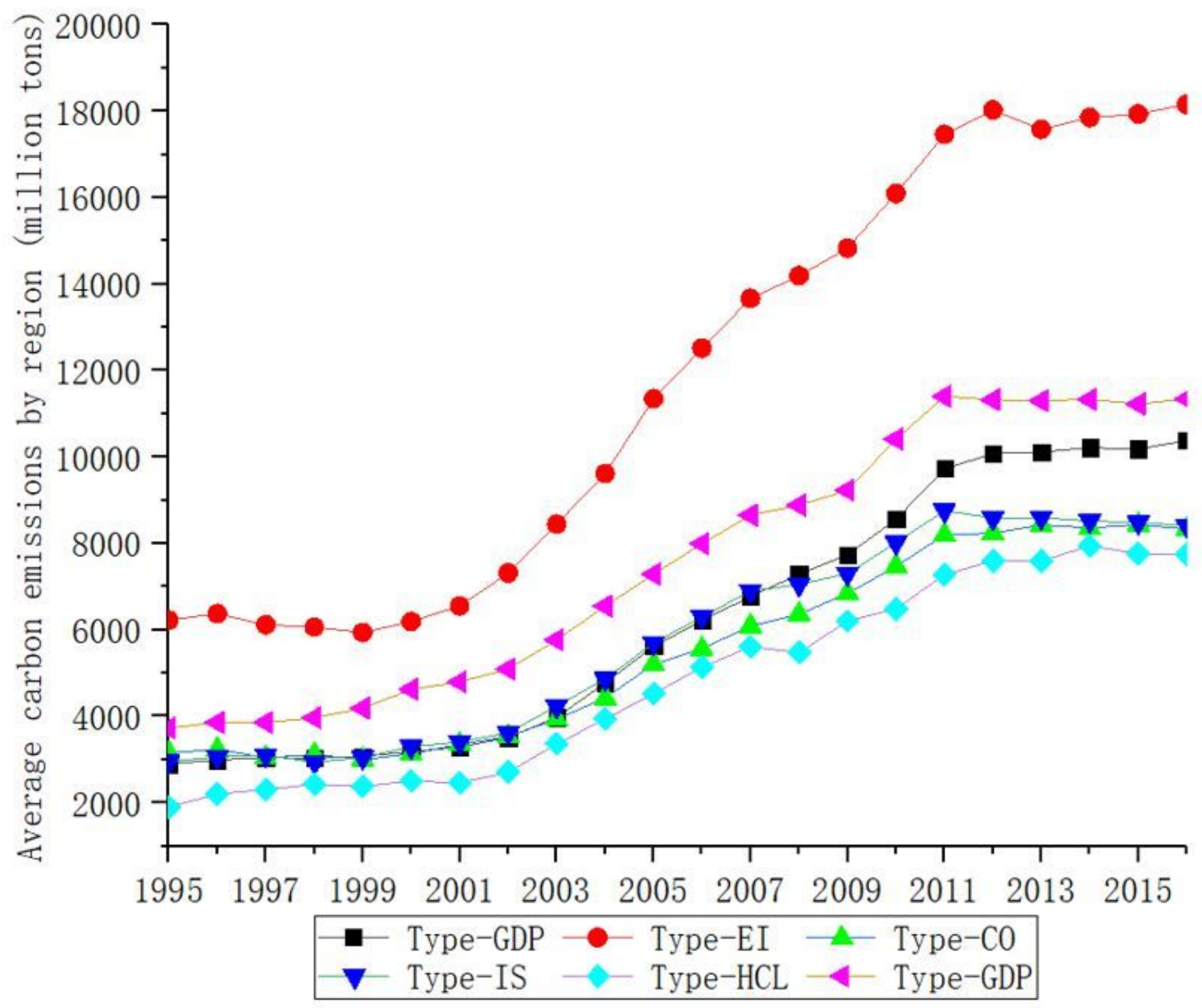

Figure 9

Average carbon emissions in each category of region. 


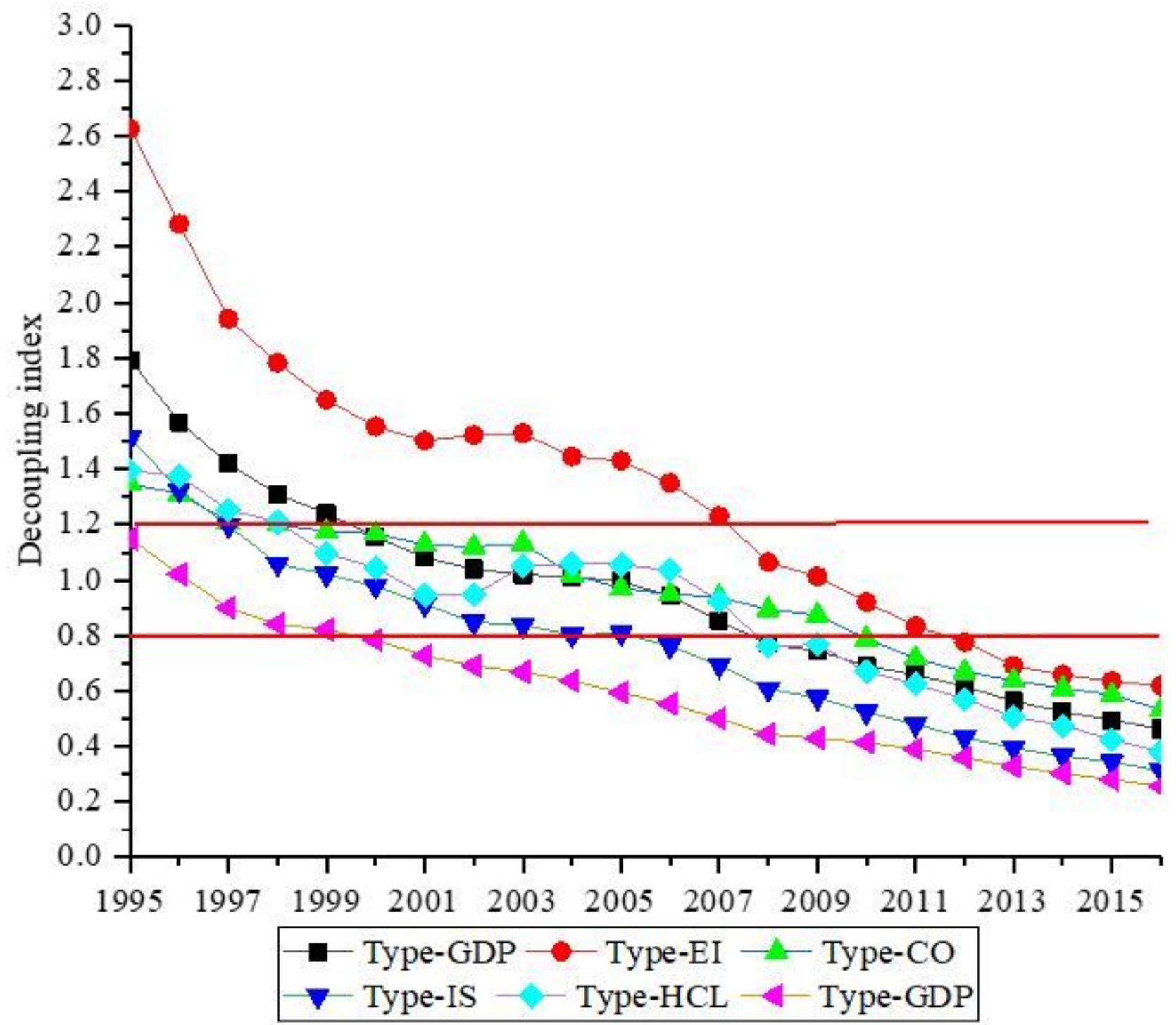

Figure 10

Decoupling index results for the six types of regions. 